\title{
Ação afirmativa e desejabilidade social ${ }^{1}$
}

\author{
Fernanda Rivera Burle ${ }^{2}$ (iD \\ Mathieu Turgeon ${ }^{3}$
}

\begin{abstract}
As políticas de ação afirmativa implementadas nas universidades públicas no Brasil abrangem três principais grupos: alunos de escolas públicas, alunos de baixa renda e alunos negros e indígenas. Opiniões sobre essa modalidade de política de ação afirmativa mais ampla, especialmente se mensuradas por perguntas diretas, podem ser enviesadas por um efeito de desejabilidade social. Este artigo procura entender se atitudes sobre diferentes tipos de políticas de ação afirmativa são propensas a um efeito de desejabilidade social e quais são os determinantes desse efeito. Para mensurar esse efeito e seus determinantes, um experimento de lista foi aplicado a 12.490 estudantes universitários em 2013. Os resultados revelam que as opiniões sobre os três tipos de políticas de ação afirmativa são propensas a um efeito de desejabilidade social. Ademais, encontramos evidências de que tanto dois determinantes individuais (interesse próprio e preconceito em relação ao grupoalvo) como um determinante contextual (áreas de conhecimento do curso universitário) explicam o efeito de desejabilidade social.

Palavras-chave: opinião pública; ação afirmativa; efeito de desejabilidade social; atitudes políticas
\end{abstract}

\section{Introdução 4}

As ações afirmativas ganharam grande notoriedade pública nos últimos anos no Brasil a partir da Lei no 12.711/2012, que reserva metade das vagas nas universidades federais para estudantes de escolas públicas, de baixa renda, negros e indígenas. Essa nova política de ação afirmativa já afetou a vida de centenas de milhares de pessoas e afetará a vida de muitas outras ainda. Apesar da importância dessa política, pouco sabemos sobre a opinião dos brasileiros e dos estudantes diretamente afetados pela política.

Mensurar opiniões sobre um tema socialmente sensível como a nova política de cotas pode ser uma tarefa difícil, uma vez que as pessoas podem não estar revelando as suas opiniões honestas. Grande parte da literatura brasileira que trata de opinião pública

\footnotetext{
${ }^{1}$ O presente artigo foi realizado com apoio da Coordenação de Aperfeiçoamento de Pessoal de Nível Superior (Capes) - Código de Financiamento 001.

2 Universidade de Brasília. Brasília (DF), Brasil. E-mail: <fernanda.burle91@gmail.com>.

3 The University of Western Ontario. London (ON), Canadá. E-mail: <mturgeo4@uwo.ca>.

${ }^{4}$ Os autores agradecem o apoio financeiro do CNPq (406090/2012-2).
} 
sobre ações afirmativas utiliza perguntas diretas (e.g., Bailey, 2004; Telles e Bailey, 2002; Smith, 2010), cujas respostas podem ser enviesadas pelo efeito de desejabilidade social: tendência que as pessoas possuem de sub ou sobreinformar suas preferências a fim de seguir as normas sociais (Blair e Imai, 2012; Streb et al., 2007). Dessa forma, quando se faz a pergunta direta e explicitamente sobre políticas de ação afirmativa, as pessoas podem preferir responder em concordância com normas sociais compartilhadas para, assim, serem vistas de maneira mais positiva pelos outros (Edwards, 1957).

Este artigo inova ao examinar o efeito de desejabilidade social nas opiniões sobre políticas de ação afirmativa, ou seja, a diferença entre o apoio declarado publicamente às ditas políticas e o apoio sincero. Mais especificamente, perguntamos: Opiniões sobre diferentes tipos de políticas de ação afirmativa são propensas a um efeito de desejabilidade social? Quem é mais suscetível ao efeito de desejabilidade social quando perguntado sobre políticas de ação afirmativa? O efeito de desejabilidade social nas opiniões sobre políticas de ação afirmativa varia de intensidade dependendo do contexto social?

Para responder a essas perguntas, analisamos o apoio às políticas de ação afirmativa entre estudantes universitários brasileiros mensurado de maneira convencional num survey e aquele mensurado a partir de um experimento de lista, em que é dada maior privacidade aos estudantes nas suas respostas. No Brasil, os poucos estudos que utilizam o experimento de lista (Turgeon, Chaves e Wives, 2014; Vidigal, 2015, 2018) concentramse apenas em um tipo de ação afirmativa, as cotas raciais. Examinamos os três tipos de política de ação afirmativa previstos na nova lei: a política de cotas raciais, a política de cotas para escolas públicas e a política de cotas sociais. Nossos achados indicam que opiniões sobre os três tipos de políticas de ação afirmativa são propensas a um efeito de desejabilidade social e que dois determinantes individuais (interesse próprio e preconceito) e um determinante contextual (áreas de conhecimento do curso universitário) explicam parcialmente esse efeito.

A seguir, em "Ação afirmativa e opinião pública no Brasil", apresentamos um quadro geral da opinião pública sobre políticas de ação afirmativa no Brasil. Na segunda seção, "Desejabilidade social e seus determinantes", discutimos os determinantes da desejabilidade social. Na terceira, "Desejabilidade social e políticas de ação afirmativa", discorremos sobre a desejabilidade social nas opiniões relativas às políticas de ação afirmativa e apresentamos algumas hipóteses a respeito disso. Na quarta, descrevemos os "Dados e métodos" utilizados, seguindo para a apresentação dos nossos "Resultados". Por fim, uma "Discussão" dos nossos achados e uma breve "Conclusão" são apresentadas.

\section{Ação afirmativa e opinião pública no Brasil}

Ação afirmativa engloba um conjunto de programas e políticas que buscam aumentar a representação de grupos historicamente sub-representados em instituições de ensino, instituições públicas e instituições privadas (Gilens, Sniderman e Kuklinski, 1998). 
No Brasil, políticas de ação afirmativa foram implementadas principalmente como sistema de cotas na admissão para as universidades federais (Jaccoud, 2008a).

As primeiras, mais famosas e polêmicas políticas de ação afirmativa no Brasil visavam a beneficiar os negros. Esse primeiro tipo de política de ação afirmativa demorou a ser adotado no país, pois acreditava-se que a miscigenação teria levado a uma inclusão de não brancos e que, assim, existiria pouco racismo no Brasil (Jaccoud, 2008b; Telles, 2012). Essa crença, denominada teoria da democracia racial, permitiu que o racismo e a desigualdade racial se perpetuassem sem que ocorresse uma interferência pública e política que solucionasse essas questões. A mudança de paradigma só começou a ocorrer a partir do período de redemocratização no Brasil e com a III Conferência Mundial contra Racismo e Discriminação Racial, realizada em Durban em 2001. Nessa conferência, o governo brasileiro reconheceu o racismo e a desigualdade racial como problemas persistentes no país e assumiu a responsabilidade de implementar políticas que lidassem com essas questões (Domingues, 2005).

Em 2001, a Assembleia Legislativa do Rio de Janeiro instituiu políticas de ação afirmativa visando a população negra na Universidade do Estado do Rio de Janeiro (Uerj) e na Universidade Estadual do Norte Fluminense (Uenf). Essas próprias universidades estaduais do Rio de Janeiro logo diversificaram as políticas de ação afirmativa, que passaram a ser destinadas tanto para negros como para alunos de escola pública (proxy para classe social) a partir de 2003 (Rio de Janeiro, 2003). Também em 2003, a Universidade de Brasília (UnB) foi a primeira universidade federal a aprovar cotas para minorias étnicas e raciais (Universidade de Brasília, 2013). Nos anos subsequentes, inúmeras outras universidades públicas começaram a implementar políticas de ação afirmativa. Cada universidade pública seguiu critérios diferentes, algumas englobando apenas raça, mas grande parte combinando raça e classe social (Feres Júnior, 2008).

Em 2012, as políticas de ação afirmativa foram instituídas em nível federal, a partir da Lei de Cotas federal (Lei no 12.711/2012). As instituições federais de educação superior ficam obrigadas a adotar políticas de ação afirmativa que tenham como alvo estudantes de escola pública, estudantes de baixa renda e estudantes negros (pardos e pretos) e indígenas. Todas as universidades públicas federais devem reservar $50 \%$ das vagas para estudantes de escola pública. Dessas vagas reservadas a estudantes de escolas públicas, $50 \%$ devem ser destinadas a estudantes de renda baixa (estudantes de famílias com renda per capita igual ou inferior a 1,5 salário mínimo). Ainda, dessas vagas reservadas a estudantes de escola pública, negros e indígenas devem preenchê-las na respectiva proporção desses grupos na unidade de federação da instituição (Brasil, 2012).

Pesquisas sobre opinião pública em relação a políticas de ação afirmativa no contexto brasileiro vêm focando principalmente nas políticas que visam os negros. Estudos vêm demonstrando que políticas de ação afirmativa para negros são apoiadas por grande parte da sociedade brasileira (e.g., Bailey, 2004; Smith, 2010). De acordo com esses estudos, o preditor mais importante dessas atitudes é a classe social, mensurada por 
escolaridade e renda (Telles e Bailey, 2002; Bailey, 2004; Smith, 2010; Bailey, Fialho e Penner, 2016). Apesar de raça ainda ser um preditor relevante, a diferença de apoio entre brancos e não brancos é muito menor do que a encontrada em estudos no contexto norteamericano. Dessa forma, a dinâmica de classe social parece fundamental na compreensão de atitudes em relação a políticas de ação afirmativa para negros. Educação, renda e raça parecem atuar conjuntamente como preditores dessas atitudes (Smith, 2010).

Todavia, esses estudos utilizaram perguntas diretas para mensurar atitudes em relação a políticas de ação afirmativa. Respostas a perguntas diretas são propensas a efeito de desejabilidade social. Entrevistados podem não estar revelando suas opiniões sinceras sobre políticas de ação afirmativa por acharem que isso vai contra as normas sociais e que, assim, poderiam ser mal vistos e interpretados.

Métodos de questionamento indireto, como o experimento de lista, podem mitigar o efeito de desejabilidade social e obter opiniões mais honestas dos respondentes. Alguns estudos no Brasil já vêm utilizando o experimento de lista para mensurar atitudes em relação às políticas de ação afirmativa (Turgeon, Chaves e Wives, 2014; Vidigal, 2015, 2018). Turgeon, Chaves e Wives (2014) utilizam o experimento de lista para mensurar as atitudes de estudantes universitários em relação a políticas de ação afirmativa para negros e indígenas. Esses autores apontam que os estudantes brancos não são suscetíveis ao efeito de desejabilidade social, mas que os estudantes negros e indígenas (grupo elegível a essa política) subinformam seu apoio a cotas raciais quando perguntados diretamente. A pesquisa de Turgeon, Chaves e Wives (2014) foi aplicada a uma amostra em 2011 e, portanto, é anterior à Lei de Cotas federal de 2012 e aos debates que advieram dela. Como esses mesmos autores reconhecem, essa nova lei pode trazer uma maior ameaça aos privilégios dos estudantes que não são elegíveis a essa política e também pode fazer com que haja uma norma social mais forte sobre a importância de políticas de ação afirmativa.

Vidigal (2015) também utiliza o experimento de lista para analisar as opiniões de estudantes universitários sobre políticas de ação afirmativa para negros e indígenas. Os resultados desse estudo, aplicado em 2013, mostram que existe um efeito de desejabilidade social na exposição dessas opiniões, inclusive para estudantes brancos. Em geral, estudantes tendem a sobreinformar a importância dessa política. Dessa forma, parece que a implementação da Lei de Cotas federal em 2012 e os debates subsequentes sobre essa questão podem ter trazido uma norma social mais forte em relação à importância de políticas de ação afirmativa e, assim, uma tendência maior ao efeito de desejabilidade social.

Esses dois estudos focam apenas em um tipo de política de ação afirmativa, a reserva de vagas para indígenas e negros. Nosso artigo inova ao estudar o efeito de desejabilidade social na opinião de estudantes universitários sobre três tipos de políticas de ação afirmativa: a política de cotas raciais, a política de cotas para escolas públicas e a política de cotas sociais. Na próxima seção, explicaremos sobre o efeito de desejabilidade social e formas de mensurá-lo. 


\section{Desejabilidade social e seus determinantes}

O efeito de desejabilidade social refere-se à tendência que as pessoas possuem de negar traços socialmente indesejáveis e admitir os socialmente desejáveis (Phillips e Clancy, 1972). Esse efeito deve ser uma preocupação real em pesquisas que utilizam o autorrelato para mensurar atitudes políticas, principalmente as que envolvem questões socialmente sensíveis, como no caso de políticas de ação afirmativa.

A desejabilidade social varia de acordo com alguns fatores, como a sensibilidade percebida da questão, o contexto social em que a questão está inserida, o grau de privacidade dado ao respondente, a proporção da população que se comporta da maneira socialmente indesejável e os aspectos específicos do projeto de pesquisa (Krumpal, 2013).

Vários estudos norte-americanos já vêm mostrando que respondentes com certas características políticas, ideológicas e sociodemográficas são mais suscetíveis ao efeito de desejabilidade social quando expressam suas atitudes explícitas e que essa relação entre característica e efeito de desejabilidade social é dependente da questão política e do contexto sociopolítico. Por exemplo, liberais e democratas, considerados mais tolerantes em relação a outras etnias e questões como ações afirmativas e imigração, na verdade possuem atitudes políticas bem parecidas com conservadores e republicanos sobre essas questões, mas são mais suscetíveis ao efeito de desejabilidade social quando autorrelatam suas atitudes (Gilens, Sniderman e Kuklinski, 1998). Janus (2010) também evidencia que indivíduos brancos não hispânicos que são liberais e/ou democratas subinformam seu apoio em relação a restrições da imigração. Existem também questões políticas que levam os conservadores a ser mais propensos ao efeito de desejabilidade social. Knoll (2013), em seu estudo sobre nativismo, encontra que os conservadores sobreinformam sua preocupação em relação aos níveis percebidos de ameaça cultural por influência de estrangeiros. Logo, dependendo da questão política e das normas sociais de cada grupo ideológico, algumas pessoas serão mais suscetíveis ao efeito de desejabilidade social do que outras.

Estudos também vêm analisando se características sociodemográficas estariam relacionadas com a propensão ao efeito de desejabilidade social, apesar de os resultados serem bem controversos e trazerem algumas inconsistências. Em relação ao gênero, Dalton e Ortegren (2011) utilizam uma escala de gerenciamento de impressões e constatam que mulheres são mais suscetíveis ao efeito de desejabilidade social. Similarmente, Gonzalez-Ocantos et al. (2012) encontram que gênero é um preditor importante do efeito de desejabilidade social no autorrelato sobre compra de voto na Nicarágua. Porém, gênero não parece ser um importante preditor do efeito de desejabilidade social no autorrelato sobre voto em eleição com candidata mulher (Streb et al., 2007). Em relação a idade e renda, os mais velhos e mais ricos são mais suscetíveis ao efeito de desejabilidade social ao autorrelatar sobre atitudes em relação ao nativismo (Knoll, 2013) e sobre compra de voto na Nicarágua (Gonzalez-Ocantos et al., 2012). 
Sobre a escolaridade, estudos que utilizam experimento de lista vêm encontrando resultados diversos da relação entre escolaridade e efeito de desejabilidade social. Respondentes com menor escolaridade parecem sobreinformar sua tolerância em relação a um candidato à presidência negro (Heerwig e McCabe, 2009) e sua preocupação em relação a níveis percebidos de ameaça cultural por influência de estrangeiros (Knoll, 2013). Já respondentes com maior nível de escolaridade parecem subinformar sobre compra de votos na Nicarágua (Gonzalez-Ocantos et al., 2012) e parecem sobreinformar sua tolerância em relação a um candidato de um grupo socialmente marginalizado (BrownIannuzzi, Najle e Gervais, 2017). Janus (2010) evidencia que a relação entre a escolaridade dos respondentes e o efeito de desejabilidade social nas suas atitudes quanto a restrições de imigração não é linear, pois depende do grau de tolerância do grupo. Nesse estudo, enquanto respondentes que possuíam o nível universitário foram mais propensos ao efeito de desejabilidade social, respondentes que possuíam o nível de pós-graduação foram menos propensos a esse efeito, pois estes já eram mais tolerantes em relação a questões de imigração.

O contexto social é outro aspecto importante a influenciar a magnitude do efeito de desejabilidade social na medida em que pode incorporar uma norma social mais forte que afeta a percepção e, consequentemente, o efeito de desejabilidade social em opiniões sobre uma determinada questão (Krumpal, 2013). Karp e Brockington (2005) constatam que cidadãos que não votaram sobreinformam em maior magnitude sobre sua participação eleitoral em países em que o nível de participação é alto do que em países em que o nível de participação é baixo. Berinsky (2002) demonstra que a magnitude do efeito de desejabilidade social nas atitudes em relação a políticas de promoção de igualdade racial de norte-americanos mudou ao longo do tempo. Isto é, tanto diferenças de contexto social entre países ou outras unidades espaciais em um mesmo momento do tempo como também diferenças de contexto social de uma mesma unidade espacial em diferentes momentos do tempo podem ser importantes.

\section{Desejabilidade social e políticas de ação afirmativa}

Nos estudos sobre ação afirmativa para negros, evidências fortes sobre o efeito da desejabilidade social em opiniões explícitas já foram encontradas. Esses estudos aconteceram principalmente no contexto norte-americano (e.g., Gilens, Sniderman e Kuklinski, 1998), mas também no Brasil (Turgeon, Chaves e Wives, 2014; Vidigal, 2015, 2018). Consideramos que esse efeito de desejabilidade social também deve ocorrer nas opiniões explícitas sobre políticas de ação afirmativa que visem outros grupos.

Nosso interesse principal é entender quais são as pessoas mais propensas a um viés de desejabilidade social. Mais especificamente: quem é mais suscetível ao efeito de desejabilidade social quando perguntado sobre políticas de ação afirmativa? 
Consideramos que existem dois fatores individuais que explicam por que as pessoas podem ser suscetíveis a um efeito de desejabilidade social ao revelarem suas opiniões sobre políticas de ação afirmativa. O primeiro fator é o interesse próprio. Interesse próprio é considerado o motivador de todos os comportamentos humanos e pode englobar tanto motivações materiais como não materiais (Kim, 2014). No caso de uma política pública como a Lei das Cotas, interesse próprio está relacionado com os benefícios e custos dessa política. Estudos vêm encontrando efeito nulo ou modesto de interesse próprio na predição de atitudes como escolha do voto e apoio a políticas públicas (e.g., Sears et al., 1980; Jacobson, 1985; Bobo, 1998). Porém, seguir o próprio interesse em atitudes em relação a políticas públicas pode ser julgado como ser egoísta ou ambicioso, características socialmente indesejáveis (Kim, 2014). Nesse sentido, pessoas que não apoiam políticas de ação afirmativa por consequência do seu interesse próprio podem não revelar sua atitude sincera quando perguntadas diretamente.

As políticas de ação afirmativa possuem características que as tornam um ótimo exemplo para estudar o efeito do interesse próprio nas opiniões. Como Sears e Funk (1990) afirmam, interesse próprio tende a influenciar atitudes políticas principalmente quando os custos e as consequências são claros e quando a questão política é percebida como importante pelos indivíduos. Políticas de ação afirmativa trazem custos e benefícios claros, isto é, os beneficiários e não beneficiários dessas políticas são tangíveis (Mangum, 2008). Isso permite que o interesse próprio possa ter uma grande importância nas atitudes sobre essas políticas, ainda mais para alunos universitários, grupo afetado por tais políticas. Dessa forma, pode ser que o interesse próprio seja um importante determinante das atitudes em relação às políticas de ação afirmativa, mas que as perguntas diretas e tradicionais sobre essas atitudes não estejam captando esse fator devido ao efeito da desejabilidade social.

Assim sendo, presumimos que o grupo não elegível ao tipo de política de ação afirmativa específico será o que tem seu interesse próprio mais prejudicado e, logo, será mais propenso ao efeito de desejabilidade social. Como cada tipo de política de ação afirmativa reserva vaga para um grupo específico, um grupo diferente estará mais suscetível a esse efeito para cada tipo de cota. Dessa forma, temos três hipóteses para interesse próprio.

Hipótese 1.1: Em relação às políticas de ação afirmativa para negros e indígenas, os estudantes universitários brancos serão os mais suscetíveis ao efeito de desejabilidade social e tenderão a sobreinformar a importância dessa política.

Hipótese 1.2: Em relação às políticas de ação afirmativa para alunos de baixa renda, os estudantes universitários de renda média, primeiramente, e de renda alta, em segundo lugar, serão os mais suscetíveis ao efeito de desejabilidade social e tenderão a sobreinformar a importância dessa política. 
Hipótese 1.3: Em relação às políticas de ação afirmativa para alunos de escola pública, os estudantes universitários que não estudaram todo o ensino médio em escola pública serão os mais suscetíveis ao efeito de desejabilidade social e tenderão a sobreinformar a importância dessa política.

Assim, estudantes universitários que pertencem ao grupo não elegível à política de ação afirmativa específica serão os mais propensos ao efeito de desejabilidade social ao revelarem suas atitudes sobre essa política. Em relação às políticas de ação afirmativa para alunos de baixa renda, consideramos que os alunos universitários de renda média serão os mais suscetíveis ao efeito de desejabilidade social, pois eles são os que têm seu interesse próprio mais afetado. Os alunos universitários de renda alta já possuem várias vantagens socioeconômicas e educacionais que os colocam numa posição vantajosa na competição por uma vaga em universidade pública, e, assim, o interesse próprio desse grupo é menos afetado pela política do que o interesse próprio de estudantes de renda média.

Acreditamos que o segundo fator individual que explica o efeito de desejabilidade social nas opiniões explícitas sobre políticas de ação afirmativa é o preconceito. $O$ preconceito está baseado na intersecção entre os estereótipos de um grupo social e os requisitos de um papel social e é dependente do contexto social (Eagly e Diekman, 2005). Essa definição de preconceito está fundamentada no estereótipo dado a um grupo social e seus membros. Como Huddy e Feldman (2009) destacam, conceber preconceito a partir de estereótipo traz uma conceituação relativamente clara e precisa sobre preconceito, em que preconceito não é confundido com outros fatores que influenciam atitudes políticas.

O preconceito pode influenciar as atitudes em relação a políticas públicas que visem um grupo específico (Peffley, Hurwitz e Sniderman, 1997). Entretanto, preconceito vai contra a norma social e, assim, as pessoas não querem parecer preconceituosas ou explicitar que suas atitudes políticas são influenciadas pelo preconceito. Dessa forma, pode ser que o preconceito seja um determinante importante das atitudes em relação a políticas de ação afirmativa, mas que perguntas de survey convencionais não consigam captá-lo. Isto é, preconceito pode ser um importante fator que explica o porquê de as pessoas não revelarem suas verdadeiras opiniões sobre políticas de ação afirmativa. Como cada tipo de política de ação afirmativa visa um grupo específico e, assim, trará um preconceito específico, temos também três hipóteses sobre preconceito.

Hipótese 2.1: Em relação às políticas de ação afirmativa para negros e indígenas, os estudantes universitários que têm preconceito em relação aos negros (preconceito racial) serão os mais suscetíveis ao efeito de desejabilidade social e tenderão a sobreinformar a importância dessa política.

Hipótese 2.2: Em relação às políticas de ação afirmativa para alunos de baixa renda, os estudantes universitários que têm preconceito em relação ao grupo que tem 
renda baixa (preconceito social) serão os mais suscetíveis ao efeito de desejabilidade social e tenderão a sobreinformar a importância dessa política.

Hipótese 2.3: Em relação às políticas de ação afirmativa para alunos de escola pública, os estudantes universitários que têm preconceito em relação às pessoas menos escolarizadas (preconceito educacional) serão os mais suscetíveis ao efeito de desejabilidade social e tenderão a sobreinformar a importância dessa política.

Logo, pressupomos, para as três cotas, que os estudantes que são mais preconceituosos em relação ao grupo-alvo da cota específica serão os mais propensos ao efeito de desejabilidade social.

Também presumimos que o contexto social influenciará o efeito de desejabilidade social nas opiniões sobre políticas de ação afirmativa. Dessa forma, perguntamos: o efeito de desejabilidade social nas opiniões sobre políticas de ação afirmativa varia de intensidade dependendo do contexto social? De acordo com Krumpal (2013), a sensibilidade de uma questão e, consequentemente, a sua propensão ao efeito de desejabilidade social dependem do contexto social em que ela está inserida. Nesse sentido, acreditamos que em contextos em que existe uma norma social mais forte sobre a importância de políticas de ação afirmativa, as pessoas devem ser mais propensas ao efeito de desejabilidade social quando revelam suas opiniões sobre essas políticas. Como nossa amostra é de estudantes universitários, comparamos as atitudes políticas dos estudantes e o efeito de desejabilidade social entre áreas de conhecimento dos cursos universitários.

Áreas de conhecimento possuem valores, crenças e normas predominantes que podem influenciar nas atitudes políticas de alunos universitários (Hastie, 2007; Fischer et al., 2017). Estudos vêm mostrando que há uma tendência de alunos de cursos de ciências sociais e de ciências humanas terem uma orientação sociopolítica mais tolerante com grupos minoritários e serem mais favoráveis a programas de bem-estar social do que alunos de engenharias (Hastie, 2007). Entretanto, pode ser que essa diferença de atitudes de alunos de diferentes áreas seja, em parte, resultado do efeito de desejabilidade social. O estudo de Gilens, Sniderman e Kuklinski (1998) mostrou que liberais e democratas possuem atitudes sobre políticas de ação afirmativa bem parecidas com conservadores e republicanos, mas que são mais suscetíveis ao efeito de desejabilidade e, assim, tendem a enviesar suas opiniões. Consideramos que o contexto dos cursos de ciências humanas traz uma norma social mais forte em relação à importância de políticas de ação afirmativa do que o contexto dos cursos de engenharias, o que, por sua vez, leva a uma maior propensão ao efeito de desejabilidade social. Logo, temos que:

Hipótese 3: Os estudantes de ciências humanas serão mais suscetíveis ao efeito de desejabilidade social do que os estudantes de engenharias e tenderão a sobreinformar a importância de políticas de ação afirmativa.

Apesar de acreditarmos que os estudantes de ciências humanas serão mais propensos ao efeito de desejabilidade social, isso não quer dizer que esses estudantes 
terão as mesmas atitudes que estudantes de engenharias. A atitude explícita dos estudantes deve ser explicada, em parte, pela atitude sincera e, em parte, pelo efeito de desejabilidade social. Dessa forma, esperamos tanto atitudes sinceras como explícitas mais favoráveis às políticas de ação afirmativa, mas também que a diferença entre esses tipos de atitudes, isto é, o viés de desejabilidade social, seja maior para estudantes de ciências humanas do que para estudantes de engenharias.

Portanto, queremos entender se políticas de ação afirmativa trazem um efeito de desejabilidade social nas atitudes em relação a essa questão e analisar se dois fatores individuais e um contextual influenciam a magnitude desse efeito. Para testarmos todas essas hipóteses, realizamos um experimento de lista em uma amostra de alunos universitários de graduação. A seguir, apresentamos os dados e o método utilizados.

\section{Dados e métodos}

A nossa pesquisa foi conduzida em 2013 e aplicada a estudantes de duas universidades públicas federais: a Universidade de Brasília (UnB) e a Universidade Federal de Minas Gerais (UFMG). Naquele momento, as duas universidades já possuíam uma política de ação afirmativa, mas estavam em processo de mudança para a implementação da Lei de Cotas federal, política de ação afirmativa mais ampla.

Todos os estudantes das duas universidades foram convidados a participar da pesquisa por e-mail e 12.490 alunos responderam ao questionário, sendo 4.422 alunos da UnB e 8.058 alunos da UFMG. Essa amostra de estudantes não representa a população estudantil brasileira nem perfeitamente o próprio grupo de estudantes das duas universidades, já que os estudantes que aceitaram participar da pesquisa podem ter características sociodemográficas e atitudes políticas que os diferenciam dos demais. A amostra da UFMG foi maior porque os estudantes foram convidados a participar da pesquisa pela própria Reitoria daquela universidade, dando maior credibilidade e importância ao estudo.

Para entendermos o efeito de desejabilidade social nas atitudes em relação a políticas de ação afirmativa, utilizamos um experimento de lista. O experimento de lista (ou técnica de contagem de item) é um tipo de experimento em survey que vem sendo usado na mensuração de inúmeros comportamentos e atitudes socialmente sensíveis, como compra de voto (Gonzalez-Ocantos et al., 2012), atitudes em relação à imigração (Janus, 2010), nativismo (Knoll, 2013), voto em eleição com candidata mulher (Streb et al., 2007), voto em eleição com candidato negro (Heerwig e McCabe, 2009; Redlawsk, Tolbert e Franko, 2010), apoio ao casamento de pessoas do mesmo sexo (Lax, Phillips e Stollwerk, 2016), preconceito racial e apoio a políticas públicas raciais (Kuklinski et al., 1997; Kuklinski, Cobb e Gilens, 1997).

O experimento de lista designa aleatoriamente uma amostra de respondentes para dois grupos: grupo-controle e grupo de tratamento. Respondentes de ambos os grupos 
recebem uma lista de itens e são perguntados sobre o número total de itens que é aplicável a eles. Entretanto, a lista apresentada para cada grupo é diferente. No grupo-controle, é apresentada ao respondente uma lista com vários itens-controle (geralmente 3 ou 4). No grupo de tratamento, é apresentada uma lista que possui os mesmos itens-controle mais o item sensível. Logo, a única diferença entre os dois grupos é que o grupo de tratamento foi exposto a um item adicional, o item sensível. Uma vez que ocorreu uma designação aleatória, os dois grupos foram equiparados em todos os aspectos possíveis e, assim, nenhum outro fator tende a interferir na relação entre esse estímulo experimental e seu efeito. A diferença das médias de resposta (número de itens escolhidos) entre os dois grupos só pode ser consequência da exposição ao item adicional e representa uma estimativa da proporção dos respondentes que concordam com o item sensível (Gilens, Sniderman e Kuklinski, 1998; Glynn, 2013).

Esse método é considerado uma técnica de agregação, pois é pedido apenas que o respondente informe a quantidade de itens com que concorda, sem identificar explicitamente quais são esses itens (Glynn, 2013; Blair, Imai e Lyall, 2014). A partir desse desenho, o experimento de lista consegue aumentar a privacidade e o anonimato do respondente e, consequentemente, mitigar o efeito de desejabilidade social (Blair, Imai e Lyall, 2014).

O experimento de lista é tradicionalmente acompanhado da inclusão da pergunta direta sobre a questão sensível, que pode ser apresentada para um terceiro grupo (e.g., Heerwig e McCabe, 2009), ou para o grupo da lista-controle (e.g., Gilens, Sniderman e Kuklinski, 1998). A partir da inclusão da pergunta direta, é possível estimar o efeito de desejabilidade social. A resposta à pergunta direta sobre o item sensível é considerada a atitude explícita do respondente, já a resposta à pergunta indireta sobre o item sensível (obtida pela comparação entre os grupos de lista-controle e de lista tratada) é considerada a atitude sincera do respondente (Knoll, 2013). A diferença entre a atitude sincera e a atitude explícita em relação à questão sensível representa o viés de desejabilidade social. No nosso artigo, utilizamos a versão com três grupos: o grupo da lista-controle, o grupo da lista tratada e o grupo da pergunta direta. Analisando as respostas obtidas para esses três grupos, conseguimos entender como o efeito de desejabilidade social se manifesta nas opiniões sobre os vários tipos de políticas de ação afirmativa.

No nosso caso, o experimento de lista foi inserido em um survey online. O survey online é um método em que os entrevistados autoadministram o questionário sem a presença do entrevistador, aumentando a privacidade dos respondentes (Krumpal, 2013). Dessa forma, o efeito de desejabilidade social do nosso artigo tende a ser subestimado (conservador) quando comparado com estudos que utilizam surveys presenciais.

O survey possui várias perguntas relativas a características sociodemográficas dos respondentes, conhecimento em relação à Lei das Cotas e estrutura racial, educacional e social no Brasil, entre outras. A questão de interesse trata da importância das cotas raciais, sociais e de escolas públicas como modo de ingresso na universidade federal. A pesquisa 
dividiu os respondentes em grupo de pergunta direta, grupo de lista-controle e grupo de lista tratada para cada um dos três tipos de cota, resultando num total de nove grupos.

Os três grupos de lista-controle (um para cada tipo de cota) receberam a mesma lista, com quatro itens-controle, apenas se diferenciando em outras perguntas presentes no survey sobre considerações e justificativas em relação ao tipo de cota específico. A seguir, apresenta-se a pergunta da lista (tanto controle como tratada) e os itens da listacontrole.

Os três grupos-controle (um para cada tipo de cota) receberam a seguinte pergunta e lista-controle:

Agora vamos falar sobre as formas de ingresso nas universidades federais brasileiras. Da seguinte lista de itens, com QUANTOS você concorda? Não precisamos saber quais, estamos interessados apenas na quantidade de itens desta lista com os quais você concorda:

(1) Todas as universidades deveriam adotar o ENEM.

(2) O aumento de número de vagas facilitou o ingresso de alunos pouco qualificados.

(3) As universidades deveriam adotar um sistema livre de ingresso sem prova.

(4) O vestibular não é uma boa prova para selecionar os melhores alunos.

Os grupos de lista tratada receberam a mesma pergunta e a lista também possuía todos os itens-controle, com a adição de um item sensível, que dependia do tipo de cota. Logo, nos três grupos de lista tratada (um para cada tipo de cota), cinco itens no total foram apresentados. A seguir, apresenta-se o item sensível da lista tratada para cada cota.

Cotas raciais:

(5) A política de reserva de vagas para negros e indígenas (política de cotas raciais) é uma política importante.

Cotas sociais:

(5) A política de reserva de vagas para alunos de baixa renda (política de cotas sociais) é uma política importante.

Cotas para escolas públicas:

(5) A política de reserva de vagas para alunos de escola pública (políticas de cotas para escolas públicas) é uma política importante.

Portanto, listas foram apresentadas para seis dos nove grupos da pesquisa. Os itens de todas as listas, tanto de listas-controle como de listas tratadas, foram apresentados de forma aleatória, para que a posição dos itens não interferisse na resposta.

A nossa lista seguiu várias recomendações de desenho apresentadas por Glynn (2013) para que os entrevistados respondessem à lista honestamente e para que o 
estimador não fosse enviesado. Todos os itens da lista tratam de um mesmo assunto, as formas de ingresso nas universidades, o que evita que os participantes descubram o objetivo da pesquisa. A lista também foi desenhada de forma a evitar o celling effect (todos os itens-controle se aplicam ao respondente) e o floor effect (nenhum dos itens-controle se aplica ao respondente), pois isso prejudicaria a privacidade dos entrevistados e, consequentemente, poderia levar a um viés na resposta (Glynn, 2013; Kuklinski, Cobb e Gilens, 1997). Utilizamos a correlação negativa entre itens da lista-controle, recomendada por Glynn (2013), que permite reduzir tanto a variância como o viés de resultados. Especificamente, os itens (1) e (3) estão correlacionados negativamente. É pouco provável que o mesmo entrevistado ache que todas as universidades devem adotar o ENEM, uma prova nacional que serve como seleção para várias universidades, ao mesmo tempo que ache que as universidades devem adotar um sistema livre de ingresso sem prova ${ }^{5}$.

Os outros três grupos receberam a pergunta direta para cada cota específica. Os respondentes deveriam apenas responder "sim" ou "não" à pergunta. A seguir, as perguntas diretas para cada tipo de cota são apresentadas.

Cotas raciais:

Você acredita que a política de reserva de vagas para negros e indígenas como forma de ingresso nas universidades federais brasileiras (políticas de cotas raciais) é uma política importante?

Cotas sociais:

Você acredita que a política de reserva de vagas para alunos de baixa renda como forma de ingresso nas universidades federais brasileiras (políticas de cotas sociais) é uma política importante?

Cotas para escolas públicas:

Você acredita que a política de reserva de vagas para alunos de escola pública como forma de ingresso nas universidades federais brasileiras (políticas de cotas para escolas públicas) é uma política importante?

A partir da comparação da resposta sobre a importância da política de ação afirmativa na pergunta direta e na pergunta indireta, calcula-se o efeito de desejabilidade social para cada cota.

Ademais, os respondentes tiveram que responder a perguntas sobre suas características sociodemográficas, como raça, renda e tipo de instituição em que

\footnotetext{
5 O experimento de lista está baseado na premissa de que o desenho não tem efeito (no design effect), isto é, que a inclusão do item sensível não altera a soma das respostas afirmativas aos itens-controle. Blair e Imai (2012) desenvolveram um teste que permite avaliar se houve violação dessa premissa. O resultado do teste indica que não há evidências do efeito de desenho e que as três listas são boas. Também estimamos as proporções populacionais de cada grupo (grupo-controle e grupo tratado) para cada valor de y (número de itens escolhidos) para cada tipo de cota. Não há nenhuma proporção negativa, o que traz maior confiança em relação à premissa de que não há efeito de desenho. Os resultados estão apresentados na Tabela C1 no Apêndice C.
} 
estudaram no ensino médio. Essas três variáveis servem para mensurar o interesse próprio. Para preconceito, utilizamos perguntas em que os entrevistados foram solicitados a indicar se frases e expressões apresentadas eram "meras brincadeiras" ou representavam preconceitos. Cada preconceito foi representado por uma expressão, uma para cada tipo de preconceito: 1) racial; 2) social; e 3) educacional. Os estudantes que indicaram que a expressão é uma mera brincadeira foram considerados preconceituosos. Essa forma de mensuração segue o entendimento de que o preconceito está baseado no estereótipo dado a um grupo e seus membros. Mensurar preconceito dessa forma permite que se diferencie esse fator de outros determinantes de atitudes políticas e que se minimizem as pressões socialmente normativas no respondente ao revelar o preconceito (Huddy e Feldman, 2009; Hodson, Rush e MacInnis, 2010; Crandall, Eshleman e O'brien, 2002). Assim, ao utilizar essa mensuração de preconceito, conseguimos maior confiança na análise da relação entre o preconceito e o efeito de desejabilidade social nas opiniões sobre políticas de ação afirmativa.

Para mensurar a influência do contexto social das áreas de conhecimento, compararemos o efeito de desejabilidade social nas opiniões explícitas sobre políticas de ação afirmativa de estudantes universitários que estão matriculados em cursos universitários de diferentes áreas de conhecimento (ciências humanas e engenharias).

Finalmente, vale notar que não foram encontradas diferenças significativas nas opiniões no nível agregado entre os estudantes da UnB e UFMG. Por essa razão e para simplificar a apresentação dos resultados, optamos por analisar os dados dessas duas universidades de forma conjunta. Utilizamos o pacote list, desenvolvido por Blair e Imai (2012), no software de análise estatística R. Esse pacote permite realizar uma análise multivariada para saber quais são os preditores do efeito de desejabilidade social.

\section{Resultados}

Antes da análise de resultados propriamente dita, verificamos se os vários grupos de tratamento do experimento estavam balanceados e também exploramos a composição da nossa amostra. A análise do balanceamento permite averiguar se a designação aleatória foi satisfatória e, assim, se podemos ter confiança em que os resultados são consequência do nosso estímulo experimental. As tabelas do Apêndice B apresentam, para cada tipo de cota, as estatísticas descritivas da amostra por grupo de tratamento e essa análise de balanceamento. Achamos apenas duas diferenças significativas entre as 63 diferenças possíveis (entre os três grupos de tratamento de cada uma das três cotas, para cada uma das sete características sociodemográficas). Essas diferenças significativas são entre o grupo de pergunta direta e o grupo de lista tratada da cota racial tanto para a renda baixa como para a renda média. Como renda não é um atributo utilizado para operacionalização das hipóteses de cota racial, essas diferenças não geram problemas para a nossa análise. 
No que concerne à composição da nossa amostra, 53,7\% dos estudantes se autodeclararam brancos, $43,0 \%$ estudaram o ensino médio em escola pública e 58,5\% eram mulheres. Em relação à renda, conforme nossa classificação, 47,0\% tinham renda baixa, 25,5\%, renda média e $27,5 \%$, renda alta. Nos grupos que receberam as questões sobre cota racial, $47,5 \%$ dos estudantes foram classificados como mais preconceituosos em relação à raça (preconceito racial). Já nos grupos que receberam as questões sobre cota social, $32,7 \%$ dos estudantes foram categorizados como mais preconceituosos em relação ao grupo que tinha baixa renda (preconceito social). Finalmente, nos grupos que receberam as questões sobre cota para escola pública, 36,9\% dos estudantes foram considerados como mais preconceituosos em relação às pessoas menos escolarizadas (preconceito educacional). Após essa apresentação das características da nossa amostra, seguimos para os nossos achados principais.

O efeito de desejabilidade social: comparando os tipos de cotas

A Figura 1 mostra graficamente a estimativa do efeito de desejabilidade social para os três tipos de cotas (cota racial, social e de escola pública). Cada gráfico possui a estimativa da proporção de pessoas que apoiam políticas de ação afirmativa quando perguntadas diretamente, a estimativa da proporção de pessoas que apoiam quando perguntadas indiretamente (ou seja, pelo experimento de lista) e a estimativa da diferença entre essas duas proporções, isto é, a estimativa do efeito de desejabilidade social. As barras ao redor das estimativas representam o intervalo de confiança de $95 \%$ gerado a partir de simulações de Monte Carlo. 
Figura 1

Efeito de desejabilidade social para os três tipos de cotas

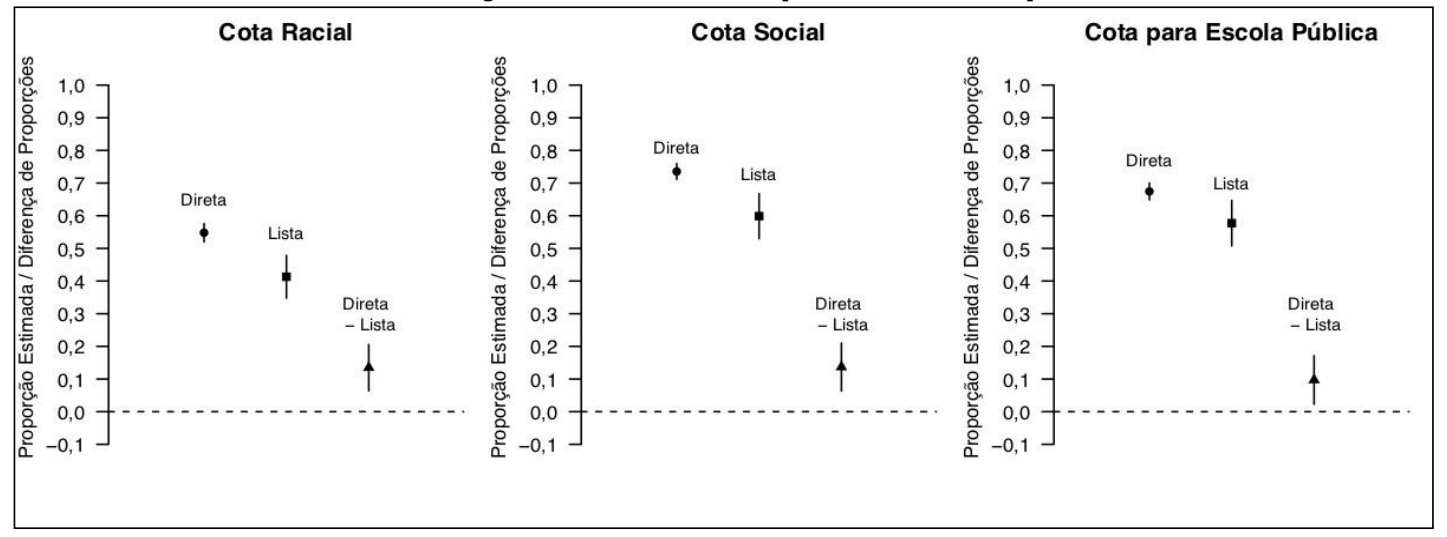

Fonte: Elaboração própria com base nos dados da pesquisa "Medindo atitudes sobre assuntos socialmente sensíveis: o caso das cotas nas universidades brasileiras" (Turgeon, 2013) ${ }^{6}$.

Primeiramente, analisando as estimativas da pergunta direta e do experimento de lista, vemos que a cota racial é a cota que possui um menor apoio, tanto se mensurado a partir do experimento de lista $(41,4 \%)$ como a partir da pergunta direta $(54,8 \%)$. Curiosamente, vemos que, da pergunta direta para o experimento de lista, a proporção de respondentes que são favoráveis à cota racial vai de uma maioria para uma minoria, o que demonstra como perguntas diretas sobre questões sensíveis podem levar a estimativas enviesadas. Já a cota para escola pública e a cota social possuem um apoio semelhante quando mensurado a partir do experimento de lista (57,7\% e 59,9\%, respectivamente), apesar de ter uma diferença um pouco maior quando o apoio é mensurado pela pergunta direta $(67,5 \%$ e $73,6 \%$, respectivamente).

O mais importante para os propósitos atuais é que encontramos um efeito substancial de desejabilidade social. Precisamente, a diferença entre a estimativa da resposta à pergunta direta (opinião explícita) e a estimativa da resposta ao experimento de lista (opinião sincera), ou seja, o efeito de desejabilidade social, é grande e positivo para os três tipos de cotas. Esse resultado indica que os estudantes tendem a demonstrar publicamente um apoio maior às políticas de cotas do que eles realmente endossam. 0 efeito de desejabilidade social é mais alto para as cotas raciais e sociais $(13,4$ e 13,7 pontos percentuais, respectivamente) e ligeiramente mais baixo para as cotas de escolas públicas (9,7 pontos percentuais).

\section{Determinantes individuais da desejabilidade social}

Nesta subseção, estudamos os fatores individuais que explicam o efeito de desejabilidade social. Apresentamos os resultados para cada cota separadamente, com o

${ }^{6}$ Dados e codebook podem ser solicitados diretamente aos autores. 
intuito de facilitar a compreensão. Especificamente, queremos saber quais características dos entrevistados estão relacionadas ao efeito de desejabilidade social.

Os dois fatores individuais principais que destacamos como explicações para o efeito de desejabilidade social são o interesse próprio e o preconceito. Desenvolvemos modelos multivariados com cinco variáveis independentes. A primeira variável é a cor ou raça do aluno, variável dicotômica que assume o valor 1 (branca), caso o respondente tenha se autodeclarado como branco pela classificação do Instituto Brasileiro de Geografia e Estatística (IBGE), e assume o valor 0, caso o respondente tenha se autodeclarado como pardo ou preto ${ }^{7}$. Essa primeira variável serve como proxy para interesse próprio no entendimento do efeito de desejabilidade social para a cota racial.

A segunda variável é renda e foi operacionalizada em três categorias: renda baixa, renda média e renda alta. A renda baixa é renda domiciliar mensal de até $R \$ 4.000,00$, que é o corte de renda aproximado para a cota social. Já a renda que não é baixa, isto é, a renda que não é elegível à cota social, foi dividida, seguindo a mediana da distribuição desse grupo, em dois subgrupos: renda média e renda alta. Essa segunda variável, por sua vez, serve como proxy para entender o papel do interesse próprio na explicação da desejabilidade social para a cota social.

A terceira variável é escola pública, variável dicotômica que assume o valor 1 , caso o respondente tenha cursado todo o ensino médio numa instituição pública (critério para ser elegível à cota para escola pública), e 0, caso o respondente não tenha cursado todo o ensino médio em escola pública ${ }^{8}$. Essa terceira variável serve como proxy para interesse próprio na compreensão do efeito de desejabilidade social para a cota para escola pública.

A quarta variável muda de acordo com o tipo de cota analisado. Essa variável trata do efeito do preconceito racial, social e educacional sobre a desejabilidade social com respeito à cota racial, social e educacional, respectivamente. Cada variável assume valor 1 para respondentes preconceituosos e valor 0 para os não preconceituosos. Essa variável foi mensurada a partir de três perguntas (uma para cada tipo de preconceito) em que os entrevistados foram solicitados a indicar se uma expressão preconceituosa relacionada a raça, classe social ou nível educacional representava uma "mera brincadeira" ou um preconceito racial, social ou educacional, respectivamente. Os alunos que indicaram que a expressão era mera brincadeira foram considerados preconceituosos. As expressões estão apresentadas no Apêndice A.

Por último, a quinta variável é gênero, variável dicotômica que assume o valor 1 , caso o respondente seja do gênero feminino, e assume o valor 0 , caso o respondente seja do gênero masculino. Essa variável serve para avaliar a suposição levantada por outros pesquisadores sobre as mulheres serem mais suscetíveis ao efeito de desejabilidade.

\footnotetext{
7 Os estudantes que se autodeclararam indígena ou amarelo foram excluídos da análise.

${ }^{8}$ Escola Não Pública inclui respondentes que cursaram o ensino médio em instituição particular, em instituição pública e particular ou no exterior.
} 
As estimativas do modelo multivariado para a pergunta direta foram geradas a partir de uma regressão logística binária, enquanto as estimativas para o experimento de lista foram geradas a partir de uma metodologia de regressão desenvolvida por Blair e Imai (2012), usando o estimador de máxima verossimilhança. As estimativas geradas por esses modelos são difíceis de interpretar e, por isso, fizemos análises gráficas para todas as variáveis de interesse a partir desses modelos multivariados. Para cada valor da variável de interesse, estimamos a proporção de apoio pela pergunta direta, a proporção de apoio pelo experimento de lista e a diferença entre essas proporções, isto é, o efeito de desejabilidade social. As Figuras 2, 3 e 4 apresentam gráficos para cada variável de interesse da análise de regressão de cota racial, social e para escola pública, respectivamente. Os detalhes sobre as estimativas desses modelos multivariados estão apresentados nas Tabelas C2, C3 e C4 do apêndice C para a cota racial, social e para escola pública, respectivamente. Novamente, as barras ao redor das estimativas representam o intervalo de confiança de $95 \%$, gerado a partir de simulações de Monte Carlo.

O primeiro gráfico da Figura 2 apresenta os resultados por autodeclaração de cor/raça, dividindo os respondentes em brancos e negros (pardos e pretos). Os respondentes que se autodeclararam brancos têm opiniões menos favoráveis sobre a cota racial do que respondentes que se autodeclararam negros, tanto quando as opiniões são mensuradas a partir da pergunta direta (48,3\% versus $63,3 \%$, respectivamente) como quando as opiniões são mensuradas a partir do experimento de lista $(38,9 \%$ versus $49,6 \%$ ). O tamanho do viés de desejabilidade social (diferença entre pergunta direta e lista) é menor para respondentes autodeclarados brancos do que para respondentes autodeclarados negros (9,4 versus 13,7 pontos percentuais, respectivamente), contrariando nossa hipótese sobre o papel do interesse próprio (hipótese 1.1). Entretanto, a diferença entre as estimativas do viés de desejabilidade social desses dois grupos não é estatisticamente significativa. O interesse próprio parece ser um determinante tanto das opiniões explícitas como das opiniões sinceras dos respondentes, mas não do efeito de desejabilidade social. Tanto respondentes autodeclarados brancos como respondentes autodeclarados negros sobreinformam o apoio a esse tipo de cota. 
Figura 2

Análise multivariada por variáveis de interesse: cota racial
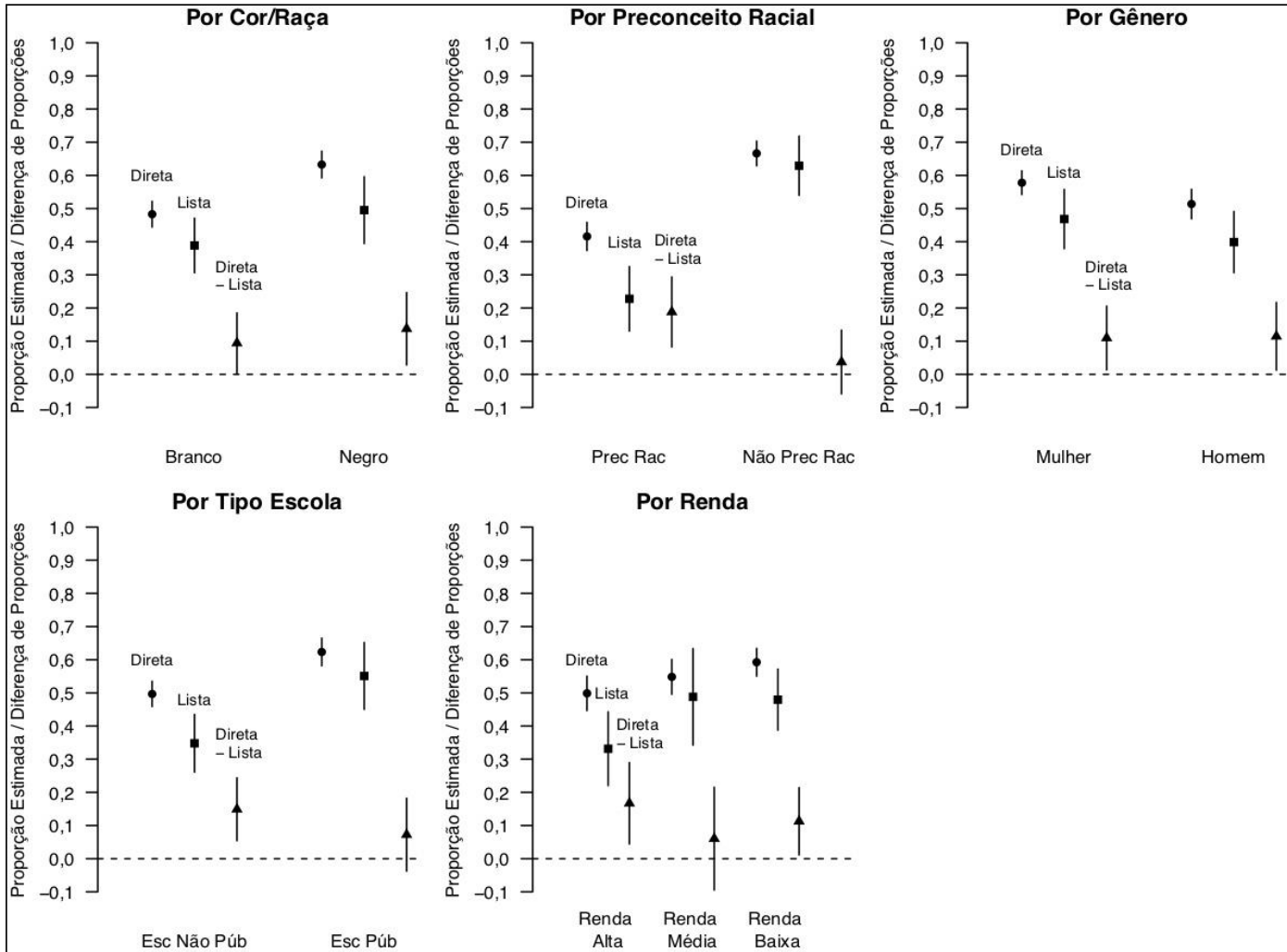

Por Renda

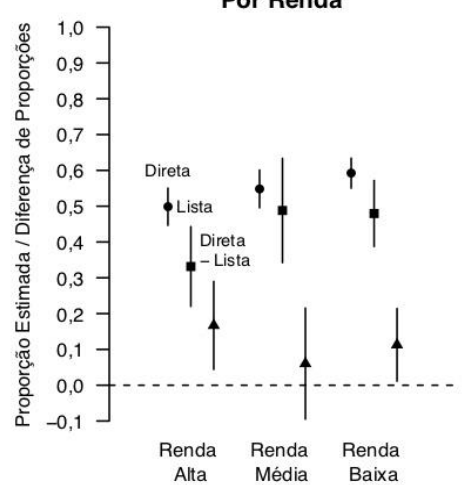

Fonte: Elaboração própria com base nos dados da pesquisa "Medindo atitudes sobre assuntos socialmente sensíveis: o caso das cotas nas universidades brasileiras" (Turgeon, 2013).

O segundo gráfico da Figura 2 apresenta a análise por preconceito racial, dividindo os respondentes em preconceituosos (Prec Rac) e não preconceituosos (Não Prec Rac). Esse é o fator individual que mostrou ser mais determinante das opiniões explícitas e sinceras sobre cota racial, além de ser um fator que explica o efeito de desejabilidade social. Os respondentes mais preconceituosos tiveram tanto opiniões explícitas $(41,6 \%$ versus $66,6 \%$ para respondentes menos preconceituosos) como opiniões sinceras (22,8\% versus $62,9 \%$ para respondentes menos preconceituosos) menos favoráveis à cota racial. Mas o resultado mais impressionante é em relação ao tamanho do viés de desejabilidade social. Enquanto esse viés é de 3,7 pontos percentuais para os menos preconceituosos (e essa estimativa não é estatisticamente significativa), o viés de desejabilidade social dos mais preconceituosos é de 18,8 pontos percentuais. A diferença entre essas duas estimativas de efeito de desejabilidade social é estatisticamente significativa. Logo, preconceito racial é um fator determinante tanto da opinião explícita e da opinião sincera 
como do efeito de desejabilidade social para cota racial, e a nossa hipótese sobre o papel do preconceito racial (hipótese 2.1) é confirmada.

O terceiro gráfico da Figura 2 apresenta a análise por gênero. Encontramos um efeito de desejabilidade de nível similar para homens e mulheres $(11,5$ versus 10,9 pontos percentuais, respectivamente), contrariando a suposição de que mulheres seriam mais suscetíveis ao efeito de desejabilidade do que homens.

O quarto gráfico da Figura 2 apresenta a análise por tipo de escola que os respondentes estudaram no ensino médio. Os resultados mostram que respondentes que estudaram em escola não pública no ensino médio (Esc Não Púb) possuem opiniões menos favoráveis em relação à cota racial do que respondentes que estudaram em escola pública (Esc Púb), tanto quando as opiniões são mensuradas a partir da pergunta direta $(49,7 \%$ versus $62,3 \%$, respectivamente) como quando as opiniões são mensuradas a partir do experimento de lista ( $34,8 \%$ versus $55,1 \%$, respectivamente). Além disso, o tamanho do viés de desejabilidade social é maior para respondentes que estudaram em escola não pública do que para respondentes que estudaram em escola pública (14,9 versus 7,2 pontos percentuais, respectivamente), apesar de a diferença entre essas estimativas não ser estatisticamente significativa.

O último e quinto gráfico da Figura 2 apresenta a análise por renda, dividindo os respondentes em renda baixa, média e alta. Os respondentes de renda baixa possuem opinião explícita mais favorável à cota racial do que respondentes de renda média ou alta. A opinião sincera dos respondentes de renda baixa também é mais favorável que a dos respondentes de renda alta, mas é praticamente a mesma que a dos respondentes de renda média. O tamanho do viés de desejabilidade social para respondentes de renda alta é levemente maior do que para respondentes de renda baixa ( 16,8 versus 11,2 pontos percentuais, respectivamente), apesar de a diferença entre essas estimativas não ser estatisticamente significativa. Não observamos um efeito de desejabilidade social para os respondentes de renda média.

Na Figura 3, apresentamos os gráficos com os resultados da análise da cota social para as mesmas variáveis de interesse. O primeiro gráfico da Figura 3 mostra o efeito da renda. Os respondentes de renda média são os que apresentam o maior tamanho de viés de desejabilidade social (29,0 pontos percentuais), bem maior do que o tamanho do viés de desejabilidade social dos respondentes de renda baixa (6,6 pontos percentuais) e dos respondentes de renda alta (7,9 pontos percentuais), os quais não são estatisticamente significativos. A diferença entre as estimativas do efeito de desejabilidade social de estudantes de renda média e estudantes de renda baixa e alta é estatisticamente significativa. A proporção estimada de respondentes de renda média favoráveis à cota social pela pergunta direta é de $75,3 \%$, nível parecido de apoio com o dos respondentes de renda baixa $(76,0 \%)$, já a proporção estimada de respondentes de renda média favoráveis à cota social pelo experimento de lista é de apenas $46,3 \%$, nível bem inferior à proporção de respondentes tanto de renda baixa $(69,5 \%)$ como de renda alta $(60,2 \%)$. 
Dessa forma, interesse próprio explica o efeito de desejabilidade social nas opiniões sobre cota social. Como esperado, respondentes de renda média são os que têm seus interesses mais prejudicados e, assim, são os mais suscetíveis ao efeito de desejabilidade social. Logo, encontramos evidências da nossa hipótese sobre o papel do interesse próprio (hipótese 1.2) para a cota social, principalmente para estudantes de renda média.

Figura 3

Análise multivariada por variáveis de interesse: cota social

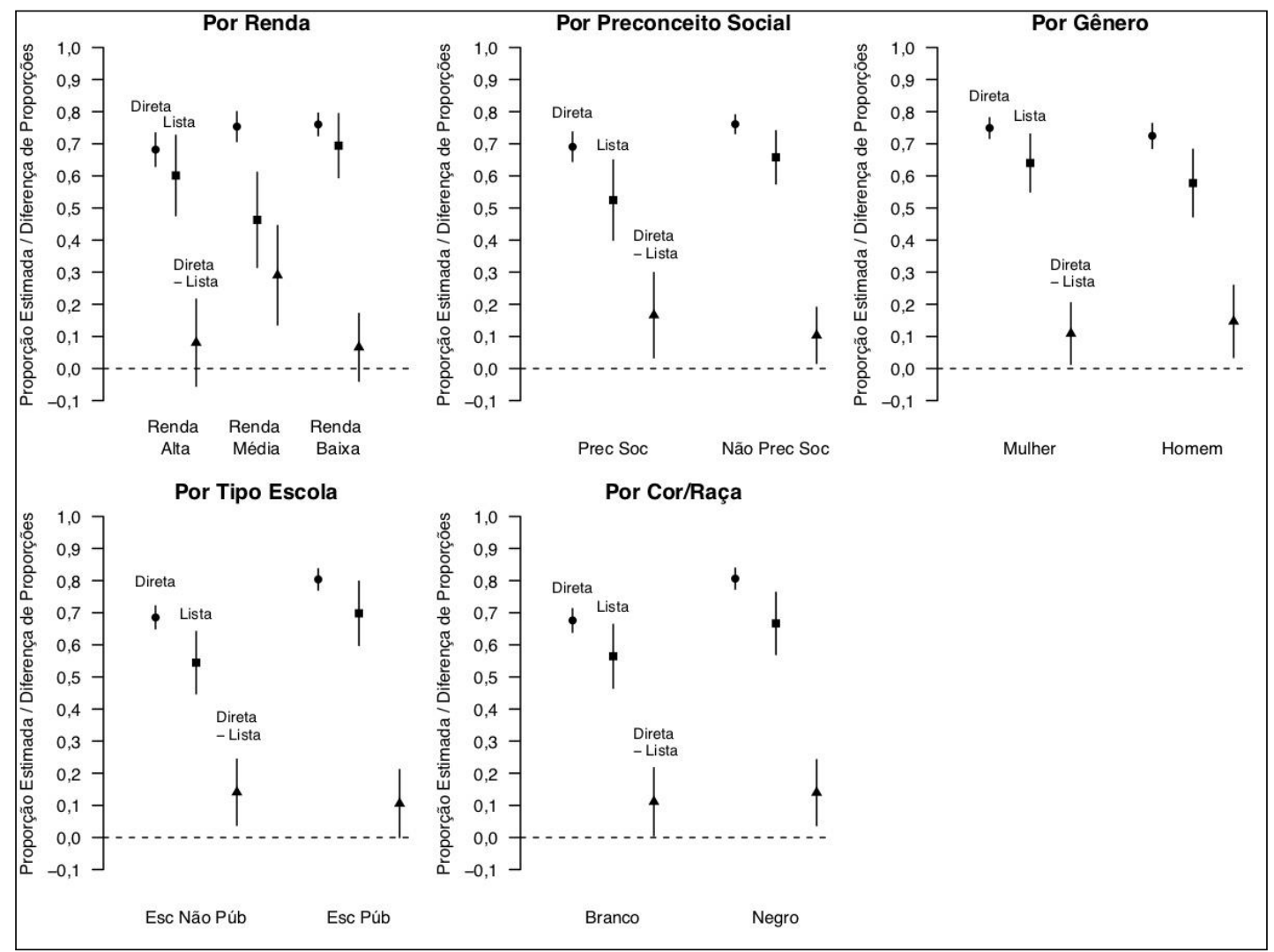

Fonte: Elaboração própria com base nos dados da pesquisa "Medindo atitudes sobre assuntos socialmente sensíveis: o caso das cotas nas universidades brasileiras" (Turgeon, 2013).

Em relação ao preconceito social, representado no segundo gráfico, o viés de desejabilidade social para os respondentes preconceituosos (Prec Soc) é de 16,7 pontos percentuais, maior do que para os respondentes não preconceituosos (Não Prec Soc), que é de 10,4 pontos percentuais. Porém, a diferença entre essas duas estimativas não é estatisticamente significativa. Logo, achamos indícios da nossa hipótese sobre o papel do preconceito social (hipótese 2.2) para a cota social.

O terceiro gráfico da Figura 3 mostra a análise por gênero. Novamente, não há diferenças notáveis entre homens e mulheres, já que ambos apresentam um efeito de 
desejabilidade social de tamanho similar. O quarto gráfico da Figura 3 mostra a análise por tipo de escola do ensino médio. A estimativa do tamanho do viés de desejabilidade social para respondentes de escola não pública (14,1 pontos percentuais) é maior do que para respondentes de escola pública (10,5 pontos percentuais), apesar de a diferença entre essas duas estimativas não ser estatisticamente significativa. O quinto gráfico mostra a análise por cor ou raça do respondente. Estudantes autodeclarados negros têm tanto opiniões explícitas como opiniões sinceras mais favoráveis à cota social do que estudantes autodeclarados brancos, mas o viés de desejabilidade para esses dois grupos é praticamente do mesmo tamanho (13,9 versus 11,2 pontos percentuais, respectivamente).

Finalmente, a Figura 4 mostra graficamente os resultados da análise da cota para escola pública. O primeiro gráfico da Figura 4 apresenta a análise do efeito de desejabilidade social por tipo de escola. A estimativa do viés de desejabilidade social para respondentes oriundos de escola não pública (11,3 pontos percentuais) é maior do que para estudantes oriundos de escola pública (6,4 pontos percentuais), apesar de a diferença entre essas duas estimativas não ser estatisticamente significativa. Assim, olhando apenas as estimativas do efeito de desejabilidade social, encontramos indícios sobre o papel do interesse próprio (hipótese 1.3) sobre a política de cota de escola pública.

O segundo gráfico da Figura 4, da análise por preconceito educacional, mostra um resultado inesperado. A estimativa do viés de desejabilidade social para os respondentes menos preconceituosos (Não Prec Edu) é de 14,1 pontos percentuais e para os respondentes mais preconceituosos (Prec Edu) é de apenas 2,2 pontos percentuais. Ou seja, os respondentes menos preconceituosos são mais suscetíveis ao efeito de desejabilidade social do que os respondentes mais preconceituosos, o que contraria a nossa hipótese 2.3 sobre o papel do preconceito educacional nas opiniões sobre cotas para escola pública. Parece que as pessoas que expressam o preconceito educacional explicitamente são as mesmas que revelam suas opiniões explícitas sobre políticas de ação afirmativa honestamente. 
Figura 4

Análise multivariada por variáveis de interesse: cota para escola pública
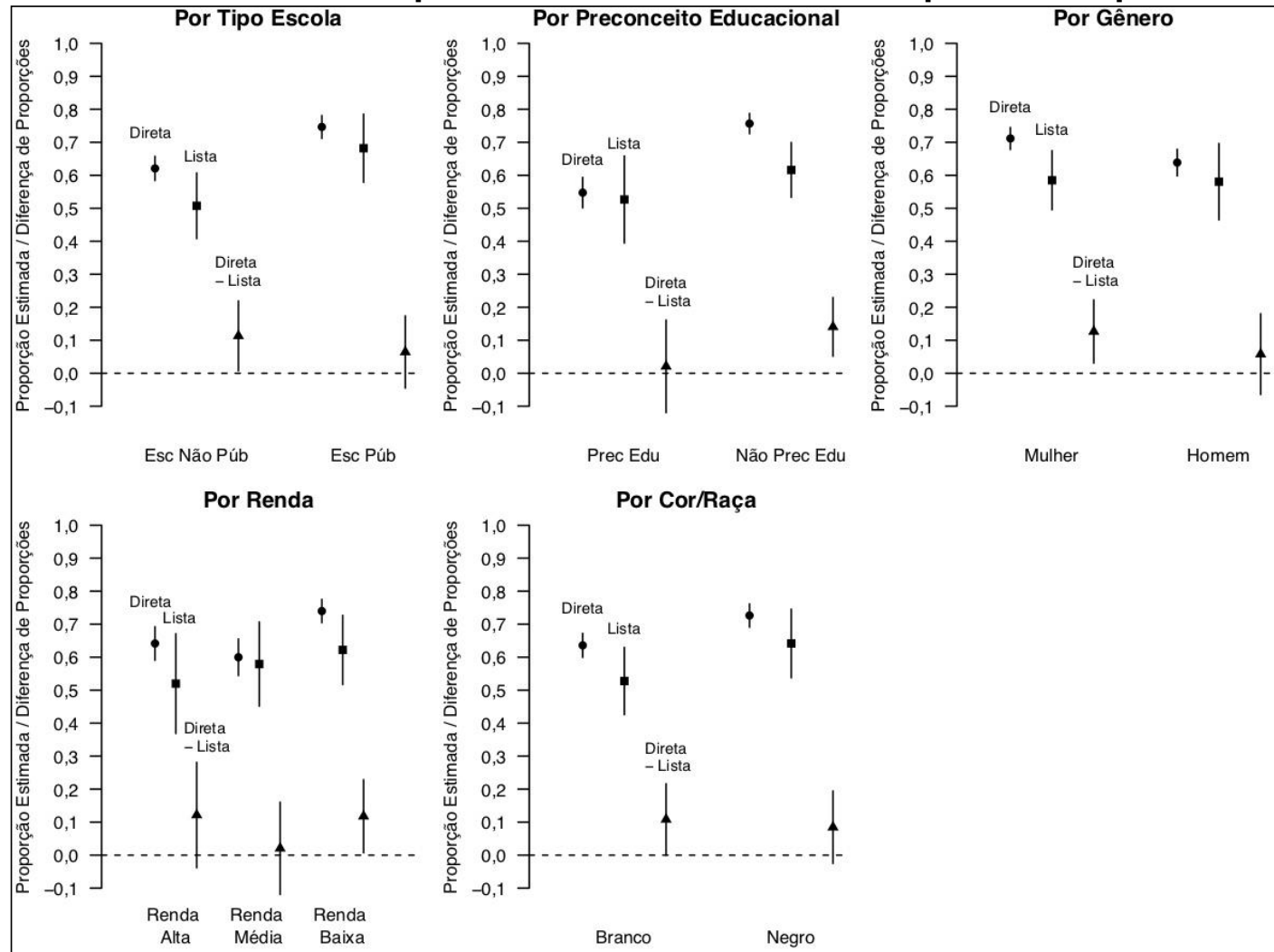

Fonte: Elaboração própria com base nos dados da pesquisa "Medindo atitudes sobre assuntos socialmente sensíveis: o caso das cotas nas universidades brasileiras" (Turgeon, 2013).

O terceiro gráfico da Figura 4 mostra a análise por gênero. Dessa vez, há um efeito de desejabilidade social para a cota para a escola pública apenas entre as mulheres - como demonstrado por outros estudiosos, e.g., Gonzalez-Ocantos et al. (2012). Porém, a diferença do efeito de desejabilidade social entre mulheres e homens não é estatisticamente significativa. O quarto gráfico da Figura 4 mostra a análise por renda. 0 tamanho do viés de desejabilidade social é significativamente diferente de 0 e maior para os respondentes de renda baixa do que para os respondentes de renda média ou alta, mas as diferenças entre essas estimativas não são estatisticamente significativas. No quinto gráfico da Figura 4, é mostrado que o tamanho do viés de desejabilidade social é praticamente o mesmo, independentemente de cor ou raça do respondente (10,9 pontos percentuais para brancos, 8,4 pontos percentuais para negros) para a cota para escola pública.

Em suma, encontramos evidências parciais sobre os dois fatores individuais que pressupomos que eram determinantes do efeito de desejabilidade social. Em relação ao 
interesse próprio, não achamos evidências da importância desse fator para o efeito de desejabilidade social nas opiniões sobre cota racial (hipótese 1.1), mas encontramos evidências significativas nas opiniões sobre cota social (hipótese 1.2) e indícios sobre cota para escola pública (hipótese 1.3). O resultado mais relevante foi em relação à cota social, em que respondentes de renda média estiveram suscetíveis a um viés de desejabilidade social de nível bem maior do que os outros grupos e, assim, o interesse próprio é uma explicação importante para o efeito de desejabilidade social.

Em relação ao preconceito, encontramos evidências fortes e estatisticamente significativas da influência do preconceito racial sobre o efeito de desejabilidade social nas opiniões sobre cota racial (hipótese 2.1), e também achamos indícios da influência do preconceito social sobre o efeito de desejabilidade social nas opiniões sobre cota social (hipótese 2.2). Isto é, respondentes mais preconceituosos em relação ao grupo-alvo dessas duas políticas tendem a sobreinformar em maior nível a importância da política específica. Entretanto, os resultados da influência do preconceito educacional sobre o efeito de desejabilidade social nas opiniões sobre cota para escola pública contradizem nossa hipótese sobre o papel do preconceito. Para a cota educacional, são os respondentes menos preconceituosos que tendem a sobreinformar em maior nível a importância dessa política. Esse resultado, porém, pode ser o produto da nossa medida mais fraca sobre o preconceito educacional, em comparação com as medidas de preconceito racial e social (ver as expressões de preconceito usadas no Apêndice A).

\section{Determinantes contextuais}

Por último, queremos saber se o tamanho do viés de desejabilidade social varia de acordo com o contexto social. Para isso, comparamos o viés de desejabilidade social de respondentes de diferentes áreas de conhecimento. A Figura 5 apresenta gráficos comparando o viés de desejabilidade social dependendo da área de conhecimento. Para essa análise, utilizamos apenas os dados da UnB e comparamos apenas os cursos de ciências humanas com os cursos de engenharias ${ }^{9}$. Consideramos os seguintes cursos da área de conhecimento de ciências humanas: ciência política, ciências sociais, filosofia, geografia, história, pedagogia e relações internacionais. Para a área de conhecimento de engenharias, consideramos os seguintes cursos: engenharia ambiental, engenharia civil, engenharia de computação, engenharia de redes de comunicação, engenharia de produção, engenharia elétrica, engenharia florestal, engenharia mecânica, engenharia mecatrônica, engenharia automotiva, engenharia de software, engenharia eletrônica e engenharia aeroespacial.

Para a cota racial, representada no primeiro gráfico da Figura 5, o tamanho do viés de desejabilidade social varia enormemente dependendo da área de conhecimento. Para

\footnotetext{
${ }^{9}$ Os dados sobre os cursos dos respondentes da UFMG estão incompletos.
} 
respondentes de ciências humanas, a proporção estimada da pergunta direta é de $72,2 \%$ e a proporção estimada do experimento de lista é de 48,7\%. A diferença entre essas proporções, isto é, a estimativa do viés de desejabilidade social, é de 23,5 pontos percentuais e é estatisticamente significativa. Já para respondentes de engenharias, a proporção estimada da pergunta direta é de $44,6 \%$ e a proporção estimada do experimento de lista é de $34,8 \%$; logo, a estimativa do viés de desejabilidade social é de 9,8 pontos percentuais, apesar de não ser estatisticamente significativa. Comparando as estimativas do viés de desejabilidade social de respondentes das duas áreas de conhecimento, vemos uma diferença expressiva para a política de cota racial. Os estudantes de ciências humanas sobreinformam a importância de políticas de ação afirmativa em nível bem maior do que estudantes de engenharia, como supomos na hipótese 3. Esse viés é ainda mais evidente se analisarmos apenas estudantes de cursos de ciência política e ciências sociais. Esses estudantes são suscetíveis a um efeito de desejabilidade social de 40,7 pontos percentuais, estimativa que é estatisticamente significativa ${ }^{10}$. Apesar disso, tanto a opinião explícita como a opinião sincera dos estudantes de ciências humanas são mais favoráveis à cota racial do que a dos estudantes de engenharias.

Para cota social, representada no segundo gráfico da Figura 5, o tamanho do viés de desejabilidade social também varia a depender da área de conhecimento do curso do estudante. Para estudantes de ciências humanas, a proporção estimada para pergunta direta é de $86,9 \%$ e a proporção estimada para o experimento de lista é de $65,3 \%$. Já para estudantes de engenharias, a proporção estimada para pergunta direta é de $68,1 \%$ e a proporção estimada para o experimento de lista é de 62,6\%. Dessa forma, a estimativa do viés de desejabilidade social para estudantes de ciências humanas é de 21,6 pontos percentuais (estimativa beirando significância estatística, provavelmente por causa do número pequeno de respondentes quando segmentamos os dados por área) e para estudantes de engenharias é de apenas 5,5 pontos percentuais (não sendo estatisticamente significativa). Esses números revelam um resultado relevante: o apoio sincero à cota social, mensurado a partir do experimento de lista, na realidade tem uma proporção estimada bem parecida entre estudantes de ciências humanas e estudantes de engenharias, mas os estudantes de ciências humanas são muito mais suscetíveis a um efeito de desejabilidade social e sobreinformam o apoio explícito à cota social, como esperado na hipótese 3 .

\footnotetext{
10 Considerando apenas respondentes de ciência política e ciências sociais, a proporção estimada pela pergunta direta é de $78,3 \%$ e a proporção estimada pelo experimento de lista é de 37,6\%.
} 
Figura 5

Efeito de desejabilidade social: comparando áreas de conhecimento

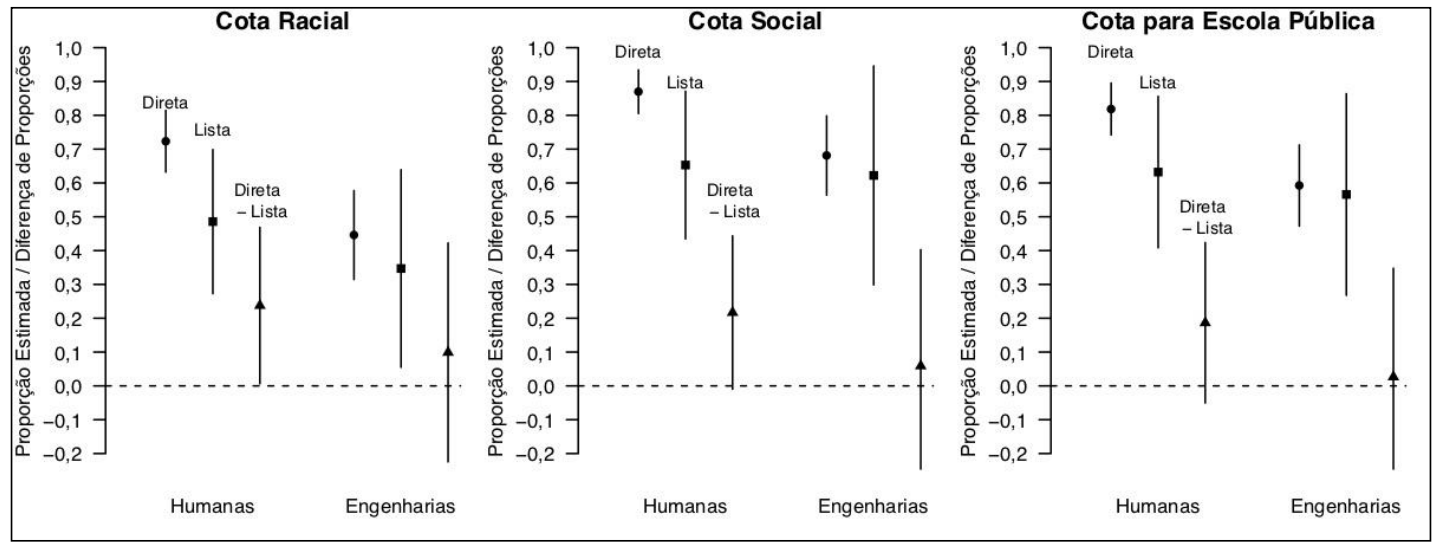

Fonte: Elaboração própria com base nos dados da pesquisa "Medindo atitudes sobre assuntos socialmente sensíveis: o caso das cotas nas universidades brasileiras" (Turgeon, 2013).

Para cota para escola pública, representada no terceiro gráfico da Figura 5, novamente a estimativa do viés de desejabilidade é bem maior para alunos de cursos de ciências humanas (18,9 pontos percentuais) do que para os de cursos de engenharias (2,3 pontos percentuais). A estimativa para área de ciências humanas é estatisticamente significativa no nível de $90 \%$, enquanto aquela para a área de engenharias não é. Assim como para cota social, a proporção de apoio sincero mensurado pelo experimento de lista é muito mais semelhante entre alunos de ciências humanas e de engenharias $(63,1 \%$ versus $56,8 \%$, respectivamente) do que a proporção de apoio explícito mensurado a partir da pergunta direta ( $82 \%$ versus $59,1 \%$, respectivamente), o que indica que os estudantes de ciências humanas estão muito mais suscetíveis ao efeito de desejabilidade social quando revelam seu apoio explícito a cota para escola pública, novamente como esperado na hipótese 3.

Assim, analisando as estimativas de efeito de desejabilidade social dos três tipos de cotas, encontramos evidências empíricas favoráveis à hipótese 3, principalmente para a cota racial, mas também para as outras duas cotas. Isto é, estudantes de ciências humanas parecem ser mais suscetíveis ao efeito de desejabilidade social do que estudantes de engenharias e tendem a sobreinformar a importância dessas políticas.

\section{Discussão e conclusão}

Este artigo procurou analisar se opiniões sobre políticas de ação afirmativa no Brasil são propensas a um efeito de desejabilidade social e quais as explicações para esse fenômeno. Nossa primeira pergunta de pesquisa foi: opiniões sobre diferentes tipos de políticas de ação afirmativa são propensas a um efeito de desejabilidade social? Os resultados mostraram que há um efeito de desejabilidade nas opiniões sobre os três tipos 
de cotas (cota racial, cota social e cota para escola pública) e que os respondentes sobreinformam a importância deles quando perguntados explicitamente. Isso evidencia a relevância de usar métodos de questionamento indireto como o experimento de lista para mensurar atitudes sobre questões sensíveis.

Descobrimos que a cota social é a que tem o maior tamanho do viés de desejabilidade social, seguida pela cota racial e, por fim, pela cota para escola pública. Cota social utiliza renda como critério, o demarcador mais importante nas relações sociais no Brasil. Além disso, a cota social e a cota para escola pública, que são as que possuem maior apoio sincero, estão diretamente relacionadas ao reconhecimento e diminuição da desigualdade social. Já para a cota racial, o menor apoio, tanto explícito como sincero, mostra que não há um reconhecimento tão marcante da desigualdade racial e, portanto, da necessidade de mitigar essa questão a partir de políticas de ação afirmativa, como no caso da desigualdade social. A diferença entre as forças dessas normas pode ser explicada tendo em vista a constatação de que, no contexto brasileiro, a desigualdade social e a desigualdade racial estão sobrepostas, o que pode tornar a questão racial menos nítida do que no contexto norte-americano, em que a sobreposição é menor.

Nossa segunda pergunta foi: quem é mais suscetível ao efeito de desejabilidade social quando perguntado sobre políticas de ação afirmativa? Em outras palavras, queríamos saber quais eram os fatores individuais que levavam os respondentes a ser mais suscetíveis ao efeito de desejabilidade social. Elaboramos hipóteses sobre dois fatores individuais principais: interesse próprio e preconceito em relação ao grupo-alvo da política.

Em relação ao interesse próprio, pressupomos que os respondentes que não são do grupo elegível à cota específica seriam os mais suscetíveis ao efeito de desejabilidade social e tenderiam a sobreinformar a importância da cota específica. Encontramos indícios de que o interesse próprio explica o efeito de desejabilidade social para cota social e cota para escola pública, mas não para cota racial.

Para cota social, os respondentes de renda média são os que apresentaram o maior tamanho do viés de desejabilidade social, ou seja, foram os que sobreinformaram em maior nível a importância dessa política, seguidos pelos respondentes de renda alta e, finalmente, pelos respondentes de renda baixa. Em relação à cota para escola pública, os respondentes de escola não pública apresentaram um maior tamanho do viés de desejabilidade social e sobreinformaram em maior nível a importância dessa política do que respondentes de escola pública. Logo, para essas duas cotas, os estudantes que tiveram seu interesse próprio mais prejudicado pela cota específica foram os que tenderam a ser mais suscetíveis ao efeito de desejabilidade social. Por fim, para cota racial, os respondentes autodeclarados negros apresentaram um viés de desejabilidade social maior que os respondentes autodeclarados brancos. Dessa forma, não encontramos evidências sobre nossa hipótese para essa cota.

Para a cota racial, pode ser que a discrepância entre o resultado e a nossa expectativa tenha ocorrido devido à forma como operacionalizamos essa questão. 
Acreditamos que as pessoas julgariam os vários tipos de cotas seguindo apenas o critério de seleção que o próprio nome da cota diz. Entretanto, segundo a Lei de Cotas federal, tanto a cota social como a cota racial estão dentro da cota para escola pública, isto é, os critérios se sobrepõem. Dessa forma, estudantes que não cursaram o ensino médio em escola pública são os que têm seu interesse mais prejudicado, pois não são elegíveis a nenhuma cota desse modelo federal. Os resultados mostram que a estimativa do viés de desejabilidade social para respondentes que não são oriundos de escola pública é sempre maior do que a estimativa do viés de desejabilidade social para estudantes de escola pública, para todos os tipos de cotas. Em suma, operacionalizando o interesse próprio dessa outra forma, há indícios de que esse fator influencia no efeito de desejabilidade social dos estudantes para os três tipos de cotas.

Em relação ao preconceito, pressupomos que os respondentes que são mais preconceituosos em relação ao grupo-alvo da cota específica seriam os mais suscetíveis ao efeito de desejabilidade social e tenderiam a sobreinformar a importância da cota específica. Achamos evidências fortes da influência do preconceito racial para cota racial e evidências parciais da influência do preconceito social para cota social. Já para a cota para escola pública, não confirmamos nossa suposição sobre a influência do preconceito educacional no efeito de desejabilidade social, provavelmente por falta de uma boa medida do preconceito educacional.

O preconceito racial é o mais conhecido e marcante na sociedade brasileira e, consequentemente, há uma norma antipreconceito racial bem forte. Assim, faz sentido que esse preconceito seja o que tenha uma maior influência no efeito de desejabilidade social. Para esse preconceito, a diferença entre as estimativas do efeito de desejabilidade social nas opiniões sobre cota racial para os respondentes preconceituosos e os não preconceituosos foi estatisticamente significativa, indicando a importância desse fator individual.

Nossa terceira e última pergunta foi: o efeito de desejabilidade social nas opiniões sobre políticas de ação afirmativa varia de intensidade dependendo do contexto social? Exploramos a influência do contexto comparando áreas de conhecimento. Verificamos que estudantes de ciências humanas apresentam um maior tamanho de viés de desejabilidade social e sobreinformam em maior nível a importância de políticas de ação afirmativa do que estudantes de engenharias para todos os tipos de cota. Esses resultados revelam que áreas de conhecimento que contêm normas sociais mais favoráveis a essas políticas podem levar os estudantes a ser suscetíveis em maior nível ao efeito de desejabilidade social quando revelam suas atitudes sobre essas políticas.

Assim, nossos resultados mostram que, em geral, respondentes tenderam a sobreinformar a importância de diferentes tipos de políticas de ação afirmativa. Além disso, apresentamos evidências de que dois fatores individuais (interesse próprio e preconceito em relação ao grupo-alvo da cota específica) e um contextual (áreas de conhecimento) explicam o efeito de desejabilidade social. 
O efeito de desejabilidade social pode enviesar resultados em pesquisas que pretendem mensurar atitudes sobre questões sensíveis e, por isso, é extremamente relevante buscar explicações para esse fenômeno. Enquanto outros estudos focaram na análise de determinantes da opinião explícita (e.g., Bailey, 2004; Smith, 2010) ou da opinião sincera (e.g., Vidigal, 2015, 2018) sobre políticas de ação afirmativa no Brasil, nosso artigo inova ao focar nos determinantes do próprio efeito de desejabilidade social. Ainda, analisamos conjuntamente o efeito de desejabilidade social nas atitudes sobre três tipos de políticas de ação afirmativa que possuem grupos diferentes como alvo. Isso foi fundamental para que operacionalizássemos os determinantes individuais e contextual do efeito de desejabilidade social de uma forma mais coordenada e abrangente, o que traz maior robustez para as nossas explicações sobre os resultados desta pesquisa.

Para compreender a opinião das pessoas sobre políticas de ação afirmativa, é necessário saber, de um lado, quais são as opiniões sinceras das pessoas e, de outro lado, quem são as pessoas que distorcem suas opiniões. Para que se desenvolvam estratégias de comunicação mais eficientes com os cidadãos, deve-se saber tanto quais são as opiniões das pessoas como quem não revela suas sinceras opiniões. A fim de entender melhor a dinâmica das relações raciais e sociais de um país, deve-se explorar tanto quais são as opiniões das pessoas como por que algumas pessoas não revelam suas sinceras opiniões. Assim, se queremos conhecer plenamente as atitudes em relação às políticas de ação afirmativa, precisamos compreender o efeito de desejabilidade social nessas atitudes e seus determinantes.

Nosso artigo traz, sinteticamente, três contribuições principais: primeiramente, demonstramos que uma metodologia incipiente permite obter opinião mais honesta das pessoas sobre questões sensíveis e mensurar o efeito de desejabilidade social; em segundo lugar, trazemos evidências empíricas sobre determinantes do efeito de desejabilidade social nas opiniões sobre ações afirmativas; em terceiro lugar, este artigo serve como uma diretriz para a análise de estudos que mensuram opinião sobre ações afirmativas de forma explícita.

No que se refere a essa terceira contribuição, nossos resultados são comparáveis aos expostos em pesquisas anteriores. O nível de apoio à cota racial mensurado pela pergunta direta na nossa pesquisa é similar ao encontrado nesses estudos que utilizaram apenas perguntas diretas (Bailey, 2004; Telles e Bailey, 2002) e que foram aplicadas em amostras mais representativas da população brasileira. Dessa forma, essas atitudes também devem estar enviesadas pelo efeito de desejabilidade social e nossa análise aponta prováveis determinantes desse viés.

Nosso artigo também possui certas limitações. A primeira limitação é consequência da aplicação do nosso survey em uma amostra de estudantes universitários que não representa a população brasileira nem o próprio conjunto de estudantes universitários. Isto é, nosso artigo traz problemas para a generalização dos resultados a outros grupos sociais. Todavia, na nossa pesquisa estávamos mais preocupados com a validade interna 
da pesquisa. Nosso interesse principal foi mensurar o efeito de desejabilidade social a partir de um experimento, em que os participantes são designados aleatoriamente para diferentes grupos de tratamento e, comparando as respostas desses grupos, conseguimos chegar às estimativas do viés de desejabilidade social.

Por serem os estudantes o grupo afetado por essa política, a opinião desse grupo é de extrema importância, ao mesmo tempo que suas atitudes podem ser diferentes da população em geral. Segundo Druckman e Kam (2011), devemos nos concentrar não apenas em dizer se a amostra de estudantes é generalizável, mas em analisar quais são suas características peculiares que podem interferir na relação causal estudada.

Podemos traçar possíveis implicações que o uso desse tipo de amostra pode trazer. Por todo o histórico dessas políticas nas universidades, a norma social sobre a importância dessa política deve ser mais forte nesse ambiente do que em outros, o que pode levar tanto a um efeito de desejabilidade social maior como a uma opinião sincera mais favorável. Por essa mesma razão, as atitudes dos estudantes sobre esse assunto podem ser mais cristalizadas do que as das pessoas em geral. Ademais, pode ser que o interesse próprio seja um determinante mais relevante para esse grupo de indivíduos do que para pessoas que não estão inseridas nesse meio social.

A segunda limitação do artigo está relacionada à dimensão temporal da generalização. A intensidade das normas sociais varia ao longo do tempo e, por conseguinte, novos estudos podem trazer diferentes resultados. O estudo de Turgeon, Chaves e Wives (2014), aplicado a uma amostra de estudantes universitários em 2011 e, portanto, anterior à Lei de Cotas federal, encontrou que estudantes negros subinformavam - apoio a cotas raciais, já estudantes brancos não eram suscetíveis ao efeito de desejabilidade social. Na nossa pesquisa, aplicada em 2013, época em que começou a implementação das cotas referentes à Lei de Cotas federal, tanto estudantes brancos como negros tenderam a sobreinformar o apoio a cotas raciais. Da mesma forma, pode ser que atualmente, depois de anos de implementação dessas cotas, haja uma norma social ainda mais forte sobre a importância delas em contextos universitários, além de um maior conhecimento adquirido sobre essa questão. Consequentemente, pode ser que tanto o tamanho do efeito de desejabilidade social como o apoio sincero a essas políticas sejam maiores hoje.

Portanto, estudos futuros devem mensurar o efeito de desejabilidade social nas opiniões sobre políticas de ação afirmativa em outras amostras (incluindo amostras nacionais), para averiguar se as tendências observadas se mantêm em outros contextos e explorar novas variáveis individuais e contextuais que podem influenciar o efeito de desejabilidade social.

Pesquisas futuras também devem utilizar o experimento de lista na mensuração de atitudes sobre outros temas sensíveis no contexto brasileiro, como questões relativas a gênero e sexualidade. No contexto norte-americano, o experimento em lista já foi utilizado em pesquisas sobre inúmeras questões sensíveis, como atitudes sobre a 
imigração (Janus, 2010) e apoio ao casamento de pessoas do mesmo sexo (Lax, Phillips e Stollwerk, 2016). Já no Brasil, o uso dessa técnica para mensurar atitudes ainda é bem incipiente. O experimento de lista é importante tanto para examinar o efeito de desejabilidade social nas opiniões explícitas sobre questões sensíveis como para mensurar opiniões sinceras sobre essas questões.

De modo mais geral, nosso artigo pretende contribuir com o entendimento de normas sociais que podem influenciar as pessoas a não expressar suas sinceras atitudes políticas. Para estar de acordo com a norma, as pessoas tendem a dar respostas que são socialmente desejáveis. Dessa forma, compreender o efeito de desejabilidade social é compreender a dinâmica das normas sociais da sociedade e como elas influenciam as atitudes dos indivíduos.

\section{Referências bibliográficas}

BAILEY, S. R. "Group dominance and the myth of racial democracy: antiracism attitudes in Brazil". American Sociological Review, vol. 69, no 5, p. 728-747, 2004.

Bailey, S. R.; Fialho, F. M.; Penner, A. M. "Interrogating race: color, racial categories, and class across the Americas". American Behavioral Scientist, vol. 60, no 4, p. 538-555, 2016.

BERINSKY, A. J. "Political context and the survey response: the dynamics of racial policy opinion". Journal of Politics, vol. 64, no 2, p. 567-584, 2002.

BlaIR, G.; ImaI, K. "Statistical analysis of list experiments". Political Analysis, vol. 20, no 1, p. 47-77, 2012.

BLAIR, G.; IMAI, K.; LYALL, J. "Comparing and combining list and endorsement experiments: evidence from Afghanistan". American Journal of Political Science, vol. 58, no 4, 1.043-1.063, 2014.

Bово, L. "Race, interests, and beliefs about affirmative action: unanswered questions and new directions". American Behavioral Scientist, vol. 41, no 7, p. 985-1.003, 1998.

BRASIL. Lei no 12.711/2012. Dispõe sobre o ingresso nas universidades federais e nas instituições federais de ensino técnico de nível médio e dá outras providências. 2012. Disponível em: <http://www.planalto.gov.br/ccivil_03/_ato2011-2014/2012/lei/l12711.htm>. Acesso em: 31 jun. 2020.

Brown-IAnnuzzi, J. L.; NAJle, M. B.; Gervais, W. M. "The illusion of political tolerance: social desirability and self-reported voting preferences". Social Psychological and Personality Science, p. 110, 2017.

CRANDAll, C. S.; Eshleman, A.; O'BRIEN, L. "Social norms and the expression and suppression of prejudice: the struggle for internalization". Journal of Personality and Social Psychology, vol. 82, no 3, p. 359, 2002.

DaLTON, D.; ORTEGREN, M. "Gender differences in ethics research: the importance of controlling for the social desirability response bias". Journal of Business Ethics, vol. 103, no 1, p. 73-93, 2011.

DOMINGUES, P. "Ações afirmativas para negros no Brasil: o início de uma reparação histórica". Revista Brasileira de Educação, vol. 29, 2005. 
FERNANDA RIVERA BURLE; MATHIEU TURGEON

DRUCKMAN, J. N.; KAM, C. D. "Students as experimental participants". Cambridge Handbook of Experimental Political Science, vol. 1, p. 41-57, 2011.

EAGLY, A. H.; DiekMAN, A. B. What is the problem? Prejudice as an attitude-in-context. Dovidio, J. F.; GLICK, P.; RUDMAN, L. A. (eds.). On the nature of prejudice: fifty years after Allport. Malden, MA: Blackwell Pub, p. 19-35, 2005.

EDWARDS, A. L. The social desirability variable in personality assessment and research. Fort Worth: Dryden Press, 1957.

FERES JúNIOR, J. "Ação afirmativa: política pública e opinião". Sinais Sociais, vol. 3, no 8, p. 38-77, 2008.

FISCHER, M., et al. "Support for free-market policies and reforms: does the field of study influence students' political attitudes?". European Journal of Political Economy, vol. 48, p. 180-197, 2017.

Gilens, M.; SNIDERMAN, P. M.; KUKLINSKI, J. H. "Affirmative action and the politics of realignment". British Journal of Political Science, vol. 28, no 1, p. 159-183, 1998.

GLYNN, A. N. "What can we learn with statistical truth serum? Design and analysis of the list experiment". Public Opinion Quarterly, vol. 77, p. 159-172, 2013.

GonzAlEZ-OCANTOS, E., et al. "Vote buying and social desirability bias: experimental evidence from Nicaragua". American Journal of Political Science, vol. 56, no 1, p. 202-217, 2012.

HASTIE, B. "Higher education and sociopolitical orientation: the role of social influence in the liberalisation of students". European Journal of Psychology of Education, vol. 22, no 3, p. 259-274, 2007.

HeERWIG, J. A.; McCABE, B. J. "Education and social desirability bias: the case of a black presidential candidate". Social Science Quarterly, vol. 90, no 3, p. 674-686, 2009.

Hodson, G.; Rush, J.; MACInNIS, C. C. "A joke is just a joke (except when it isn't): cavalier humor beliefs facilitate the expression of group dominance motives". Journal of Personality and Social Psychology, vol. 99, no 4, p. 660, 2010.

HudDY, L.; Feldman, S. "On assessing the political effects of racial prejudice". Annual Review of Political Science, vol. 12, p. 423-447, 2009.

JACCOUD, L. "O combate ao racismo e à desigualdade: o desafio das políticas públicas de promoção da igualdade racial". As políticas públicas e a desigualdade racial no Brasil, vol. 120, p. 131-166, 2008a.

. "Racismo e República: o debate sobre o branqueamento e a discriminação racial no Brasil". As políticas públicas e a desigualdade racial no Brasil, vol. 120, p. 45-64, $2008 \mathrm{~b}$.

JACOBSON, C. K. "Resistance to affirmative action: self-interest or racism?". Journal of Conflict Resolution, vol. 29, no 2, p. 306-329, 1985.

JANUS, A. L. "The influence of social desirability pressures on expressed immigration attitudes". Social Science Quarterly, vol. 91, no 4, p. 928-946, 2010.

KARP, J. A.; BROCKINGTON, D. "Social desirability and response validity: a comparative analysis of overreporting voter turnout in five countries". Journal of Politics, vol. 67, n 3, p. 825-840, 2005.

KIM, A. "The curious case of self-interest: inconsistent effects and ambivalence toward a widely accepted construct". Journal for the Theory of Social Behaviour, vol. 44, n 1, 99-122, 2014. 
KNOLL, B. R. "Assessing the effect of social desirability on nativism attitude responses". Social Science Research, vol. 42, nº 6, p. 1.587-1.598, 2013.

KRUMPAL, I. "Determinants of social desirability bias in sensitive surveys: a literature review". Quality \& Quantity, vol. 47, no 4, p. 2.025-2.047, 2013.

KUKLINSKI, J. H.; CoBB, M. D.; GILENS, M. "Racial attitudes and the 'New South'". The Journal of Politics, vol. 59, no 2, p. 323-349, 1997.

KUKLINSKI, J. H., et al. "Racial prejudice and attitudes toward affirmative action". American Journal of Political Science, p. 402-419, 1997.

LAX, J. R.; Phillips, J. H.; Stollwerk, A. F. "Are survey respondents lying about their support for same-sex marriage? Lessons from a list experiment". Public Opinion Quarterly, vol. 80, no 2, p. 510533, 2016.

MANGUM, M. "Testing competing explanations of black opinions on affirmative action". Policy Studies Journal, vol. 36, no 3, p. 347-366, 2008.

Peffley, M.; Hurwitz, J.; Sniderman, P. M. "Racial stereotypes and whites' political views of blacks in the context of welfare and crime". American Journal of Political Science, p. 30-60, 1997.

PhILliPS, D. L.; CLANCY, K. J. "Some effects of 'social desirability' in survey studies". American Journal of Sociology, vol. 77, no 5, p. 921-940, 1972.

Redlawsk, D. P.; Tolbert, C. J.; Franko, W. "Voters, emotions, and race in 2008: Obama as the first black president". Political Research Quarterly, vol. 63, no 4, p. 875-889, 2010.

RIO DE JANEIRO. Lei no 4151/2003. Institui nova disciplina sobre o sistema de cotas para ingresso nas universidades públicas estaduais e dá outras providências. Rio de Janeiro, 4 set. 2003.

SEARS, D. O.; FunK, C. L. "The limited effect of economic self-interest on the political attitudes of the mass public". Journal of Behavioral Economics, vol. 19, no 3, p. 247-271, 1990.

SEARS, D. O., et al. "Self-interest vs. symbolic politics in policy attitudes and presidential voting". American Political Science Review, vol. 74, no 3, p. 670-684, 1980.

SмIтH, A. "Who supports affirmative action in Brazil?". Americas Barometer Insights, vol. 49, p. 1-8, 2010.

Streb, M. J., et al. "Social desirability effects and support for a female American president". Public Opinion Quarterly, vol. 72, no 1, p. 76-89, 2007.

TELLES, E. E. O significado da raça na sociedade brasileira. Trad. A. A. Callado. Versão divulgada na internet. Princeton: Princeton University Press, 2012.

Telles, E.; BAILeY, S. "Políticas contra o racismo e opinião pública: comparações entre Brasil e Estados Unidos". Opinião Pública, vol. 8, no 1, p. 30-39, 2002.

TURGEON, M. "Medindo atitudes sobre assuntos socialmente sensíveis: o caso das cotas nas universidades brasileiras" (banco de dados e codebook), 2013.

Turgeon, M.; Chaves, B. S.; Wives, W. W. "Políticas de ação afirmativa e o experimento de listas: o caso das cotas raciais na universidade brasileira". Opinião Pública, vol. 20, no 3, p. 363-376, 2014.

UniversidAde de BRAsília. Análise do sistema de cotas para negros na Universidade de Brasília. Decanato de ensino de graduação, Universidade de Brasília, Brasília, 2013. 
VIDIGAL, R. L. B. P. "Medindo assuntos socialmente sensíveis: o uso do experimento de lista e políticas de ação afirmativa". Revista Eletrônica de Ciência Política, vol. 6, nº 1, 2015.

. "Affirmative action attitudes of whites: evidence from a list experiment survey in Brazil". Brazilian Political Science Review, vol. 12, no 2, 2018.

\section{Apêndice A}

\section{Expressões preconceituosas}

Seguem abaixo uma série de frases e expressões brasileiras que se ouvem na rua, na televisão, no rádio, entre amigos e familiares. Na sua opinião, as seguintes frases e expressões são preconceituosas ou meras brincadeiras:

- Cabelo ruim é igual bandido... Ou tá preso ou tá armado.

- Filho de rico é Playboy, filho de pobre é Office-boy.

- Por traz de todo concerteza e agente existe um Ensino Fundamental incompleto.

\section{Apêndice B}

Tabela B1

Análise do balanceamento entre grupos de tratamento para cota racial (\%)

\begin{tabular}{|l|c|c|c|}
\hline \multirow{2}{*}{$\begin{array}{l}\text { Característica } \\
\text { sociodemográfica }\end{array}$} & $\begin{array}{c}\text { Pergunta direta } \\
\text { (e.p.) }\end{array}$ & $\begin{array}{c}|c| \\
\text { Grupo tratado } \\
\text { (e.p.) }\end{array}$ & $\begin{array}{c}\text { Grupo-controle } \\
\text { (e.p.) }\end{array}$ \\
\cline { 3 - 4 } Raça branca & $\begin{array}{c}54,0 \\
(1,4)\end{array}$ & $\begin{array}{c}53,1 \\
(1,4)\end{array}$ & $\begin{array}{c}54,9 \\
(1,4)\end{array}$ \\
\hline Renda baixa & 42,6 & $48,2 *$ & 45,3 \\
& $(1,4)$ & $(1,5)$ & $(1,5)$ \\
\hline Renda média & 28,2 & $23,6 *$ & 26,5 \\
& $(1,3)$ & $(1,2)$ & $(1,3)$ \\
\hline Renda alta & 29,2 & 28,2 & 28,3 \\
& $(1,3)$ & $(1,3)$ & $4,3)$ \\
\hline Escola pública & 42,1 & 42,5 & $(1,4)$ \\
\hline Mulher & $(1,4)$ & $(1,4)$ & 58,3 \\
\hline Preconceito racial & 61,2 & 59,2 & $(1,4)$ \\
\hline N & $(1,3)$ & $(1,4)$ & 49,5 \\
& 45,9 & 47,2 & $(1,4)$ \\
\hline
\end{tabular}

Fonte: Elaboração própria com base nos dados da pesquisa "Medindo atitudes sobre assuntos socialmente sensíveis: o caso das cotas nas universidades brasileiras" (Turgeon, 2013).

Nota: * indica que a diferença com o grupo da pergunta direta é estatisticamente significativa para o nível 0,05 (bicaudal). 
Tabela B2

Análise do balanceamento entre grupos de tratamento para cota social $(\%)$

\begin{tabular}{|c|c|c|c|}
\hline \multirow[b]{2}{*}{$\begin{array}{l}\text { Característica } \\
\text { sociodemográfica }\end{array}$} & \multirow[b]{2}{*}{$\begin{array}{l}\text { Pergunta } \\
\text { direta } \\
\text { (e.p.) }\end{array}$} & \multicolumn{2}{|c|}{ Experimento de lista } \\
\hline & & $\begin{array}{l}\text { Grupo tratado } \\
\text { (e.p.) }\end{array}$ & $\begin{array}{c}\text { Grupo-controle } \\
\text { (e.p.) }\end{array}$ \\
\hline Raça branca & $\begin{array}{l}54,0 \\
(1,4)\end{array}$ & $\begin{array}{l}56,2 \\
(1,4)\end{array}$ & $\begin{array}{l}53,0 \\
(1,4)\end{array}$ \\
\hline Renda baixa & $\begin{array}{l}48,0 \\
(1,4)\end{array}$ & $\begin{array}{l}47,1 \\
(1,5)\end{array}$ & $\begin{array}{l}48,3 \\
(1,4)\end{array}$ \\
\hline Renda média & $\begin{array}{l}27,1 \\
(1,3)\end{array}$ & $\begin{array}{l}26,0 \\
(1,3)\end{array}$ & $\begin{array}{l}24,3 \\
(1,2)\end{array}$ \\
\hline Renda alta & $\begin{array}{l}24,9 \\
(1,2)\end{array}$ & $\begin{array}{l}26,9 \\
(1,3)\end{array}$ & $\begin{array}{l}27,3 \\
(1,3)\end{array}$ \\
\hline Escola pública & $\begin{array}{l}44,2 \\
(1,4)\end{array}$ & $\begin{array}{l}42,1 \\
(1,4)\end{array}$ & $\begin{array}{l}42,8 \\
(1,4)\end{array}$ \\
\hline Mulher & $\begin{array}{l}57,4 \\
(1,3)\end{array}$ & $\begin{array}{l}58,6 \\
(1,4)\end{array}$ & $\begin{array}{l}56,3 \\
(1,4)\end{array}$ \\
\hline Preconceito social & $\begin{array}{l}31,7 \\
(1,3)\end{array}$ & $\begin{array}{l}32,2 \\
(1,3)\end{array}$ & $\begin{array}{l}34,3 \\
(1,4)\end{array}$ \\
\hline $\mathrm{N}$ & 1359 & 1312 & 1324 \\
\hline
\end{tabular}

Fonte: Elaboração própria com base nos dados da pesquisa "Medindo atitudes sobre assuntos socialmente sensíveis: o caso das cotas nas universidades brasileiras" (Turgeon, 2013).

Nota: * indica que a diferença com o grupo da pergunta direta é estatisticamente significativa ao nível 0,05 (bicaudal). 
Tabela B3

Análise do balanceamento entre grupos de tratamento para cota para escola pública (\%)

\begin{tabular}{|c|c|c|c|}
\hline \multirow[b]{2}{*}{$\begin{array}{l}\text { Característica } \\
\text { sociodemográfica }\end{array}$} & \multirow[b]{2}{*}{$\begin{array}{c}\text { Pergunta direta } \\
\text { (e.p.) }\end{array}$} & \multicolumn{2}{|c|}{ Experimento de lista } \\
\hline & & $\begin{array}{c}\text { Grupo tratado } \\
\text { (e.p.) }\end{array}$ & $\begin{array}{c}\text { Grupo- } \\
\text { controle } \\
\text { (e.p.) }\end{array}$ \\
\hline Raça branca & $\begin{array}{l}53,2 \\
(1,4)\end{array}$ & $\begin{array}{l}51,7 \\
(1,4)\end{array}$ & $\begin{array}{l}53,3 \\
(1,4)\end{array}$ \\
\hline Renda baixa & $\begin{array}{l}49,0 \\
(1,4)\end{array}$ & $\begin{array}{l}46,7 \\
(1,4)\end{array}$ & $\begin{array}{l}47,4 \\
(1,5)\end{array}$ \\
\hline Renda média & $\begin{array}{l}23,9 \\
(1,2)\end{array}$ & $\begin{array}{l}25,4 \\
(1,3)\end{array}$ & $\begin{array}{l}24,8 \\
(1,3)\end{array}$ \\
\hline Renda alta & $\begin{array}{l}27,2 \\
(1,3)\end{array}$ & $\begin{array}{l}27,9 \\
(1,3)\end{array}$ & $\begin{array}{l}27,7 \\
(1,3)\end{array}$ \\
\hline Escola pública & $\begin{array}{l}44,9 \\
(1,4)\end{array}$ & $\begin{array}{l}42,3 \\
(1,4)\end{array}$ & $\begin{array}{l}42,0 \\
(1,4)\end{array}$ \\
\hline Mulher & $\begin{array}{l}56,7 \\
(1,4)\end{array}$ & $\begin{array}{l}59,5 \\
(1,3)\end{array}$ & $\begin{array}{l}59,0 \\
(1,4)\end{array}$ \\
\hline $\begin{array}{l}\text { Preconceito } \\
\text { educacional }\end{array}$ & $\begin{array}{l}37,2 \\
(1,4)\end{array}$ & $\begin{array}{l}35,9 \\
(1,4)\end{array}$ & $\begin{array}{l}37,7 \\
(1,4)\end{array}$ \\
\hline $\mathrm{N}$ & 1346 & 1339 & 1269 \\
\hline
\end{tabular}

Fonte: Ėlaboração própria com base nos dados da pesquisa "Medindo atitudes sobre assuntos socialmente sensíveis: o caso das cotas nas universidades brasileiras" (Turgeon, 2013).

Nota: * indica que a diferença com o grupo da pergunta direta é estatisticamente significativa ao nível 0,05 (bicaudal).

\section{Apêndice C}

Tabela C1

Teste para efeito de desenho de experimento de lista

\begin{tabular}{|l|c|c|c|c|c|c|}
\hline \multirow{2}{*}{ Valor do Y } & \multicolumn{2}{|c|}{ Cota racial } & \multicolumn{2}{c|}{ Cota social } & \multicolumn{2}{c|}{ Cota para escola pública } \\
\cline { 2 - 7 } & $\begin{array}{c}\text { Grupo } \\
\text { controle } \\
\text { est.(e.p.) }\end{array}$ & $\begin{array}{c}\text { Grupo tratado } \\
\text { est.(e.p.) }\end{array}$ & $\begin{array}{c}\text { Grupo- } \\
\text { controle } \\
\text { est.(e.p.) }\end{array}$ & $\begin{array}{c}\text { Grupo tratado } \\
\text { est.(e.p.) }\end{array}$ & $\begin{array}{c}\text { Grupo- } \\
\text { controle } \\
\text { est.(e.p.) }\end{array}$ & $\begin{array}{c}\text { Grupo tratado } \\
\text { est.(e.p.) }\end{array}$ \\
\hline 0 & $0,132(0,011)$ & $0,033(0,016)$ & $0,058(0,007)$ & $0,150(0,014)$ & $0,083(0,008)$ & $0,107(0,015)$ \\
\hline 1 & $0,247(0,019)$ & $0,177(0,022)$ & $0,134(0,019)$ & $0,235(0,021)$ & $0,144(0,019)$ & $0,254(0,021)$ \\
\hline 2 & $0,128(0.021)$ & $0,157(0,017)$ & $0,102(0,021)$ & $0,187(0,018)$ & $0,114(0,021)$ & $0,155(0,018)$ \\
\hline 3 & $0,038(0,014)$ & $0,060(0,010)$ & $0,034(0,014)$ & $0,065(0,011)$ & $0,041(0,015)$ & $0,070(0,011)$ \\
\hline 4 & $0,006(0,007)$ & $0,023(0,005)$ & $0,006(0,008)$ & $0,029(0,005)$ & $0,006(0,008)$ & $0,027(0,005)$ \\
\hline Total & 0,550 & 0,450 & 0,334 & 0,666 & 0,387 & 0,613 \\
\hline
\end{tabular}

Fonte: Elaboração própria com base nos dados da pesquisa "Medindo atitudes sobre assuntos socialmente sensíveis: o caso das cotas nas universidades brasileiras" (Turgeon, 2013). 
Tabela C2

Modelo multivariado para cota racial

\begin{tabular}{|c|c|c|c|}
\hline \multirow[b]{2}{*}{ Variáveis } & \multirow{2}{*}{$\begin{array}{l}\text { Pergunta direta } \\
\text { Est.(e.p.) }\end{array}$} & \multicolumn{2}{|c|}{ Experimento de lista } \\
\hline & & $\begin{array}{c}\text { Item sensível } \\
\text { est.(e.p.) }\end{array}$ & $\begin{array}{c}\text { Itens-controle } \\
\text { est.(e.p.) }\end{array}$ \\
\hline Cor/ Raça Branca & $\begin{array}{c}-0,501^{* * *} \\
(0,133)\end{array}$ & $\begin{array}{l}-0,219 \\
(0,360)\end{array}$ & $\begin{array}{c}-0,110^{*} \\
(0,058)\end{array}$ \\
\hline Renda Baixa & $\begin{array}{c}0,079 \\
(0,159)\end{array}$ & $\begin{array}{l}-0,317 \\
(0,461)\end{array}$ & $\begin{array}{c}0,100 \\
(0,073)\end{array}$ \\
\hline Renda Alta & $\begin{array}{l}-0,091 \\
(0,170)\end{array}$ & $\begin{array}{l}-0,521 \\
(0,513)\end{array}$ & $\begin{array}{c}0,093 \\
(0,080)\end{array}$ \\
\hline Escola Pública & $\begin{array}{l}0,279 * \\
(0,143)\end{array}$ & $\begin{array}{c}0,835 * * \\
(0,376)\end{array}$ & $\begin{array}{c}0,041 \\
(0,062)\end{array}$ \\
\hline Gênero (Mulher) & $\begin{array}{c}0,162 \\
(0,130)\end{array}$ & $\begin{array}{c}0,287 \\
(0,348)\end{array}$ & $\begin{array}{c}-0,163^{* * *} \\
(0,057)\end{array}$ \\
\hline Preconceito Racial & $\begin{array}{c}-1,020 * * * \\
(0,128)\end{array}$ & $\begin{array}{c}-1,853 * * * \\
(0,379)\end{array}$ & $\begin{array}{c}-0,261 * * * \\
(0,058)\end{array}$ \\
\hline Intercepto & $\begin{array}{c}0,736 * * * \\
(0,191)\end{array}$ & $\begin{array}{c}0,410 \\
(0,536)\end{array}$ & $\begin{array}{c}-0,431 * * * \\
(0,086)\end{array}$ \\
\hline Observações & 1312 & \multicolumn{2}{|c|}{2620} \\
\hline
\end{tabular}

Fonte: Ėlaboração própria com base nos dados da pesquïsa "Medindo atitudes sobre assuntos socialmente sensíveis: o caso das cotas nas universidades brasileiras" (Turgeon, 2013).

Nota: $* \mathrm{p}<0,1 ; * * \mathrm{p}<0,05 ; * * * \mathrm{p}<0,01$. 
Tabela C3

Modelo multivariado para cota social

\begin{tabular}{|c|c|c|c|}
\hline \multirow{2}{*}{ Variáveis } & \multirow{2}{*}{$\begin{array}{c}\text { Pergunta } \\
\text { direta } \\
\text { est.(e.p.) }\end{array}$} & \multicolumn{2}{|c|}{ Experimento de lista } \\
\hline & & $\begin{array}{c}\text { Item sensivel } \\
\text { est.(e.p.) }\end{array}$ & $\begin{array}{c}\text { Itens-controle } \\
\text { est.(e.p.) }\end{array}$ \\
\hline Cor/raça branca & $\begin{array}{c}-0,586^{* * *} \\
(0,145)\end{array}$ & $\begin{array}{l}-0,307 \\
(0,336)\end{array}$ & $\begin{array}{l}-0,019 \\
(0,059)\end{array}$ \\
\hline Renda baixa & $\begin{array}{l}-0,166 \\
(0,173)\end{array}$ & $\begin{array}{l}0,892^{* *} \\
(0,425)\end{array}$ & $\begin{array}{l}-0,072 \\
(0,075)\end{array}$ \\
\hline Renda alta & $\begin{array}{l}-0,192 \\
(0,188)\end{array}$ & $\begin{array}{c}0,794^{*} \\
(0,455)\end{array}$ & $\begin{array}{l}-0,114 \\
(0,082)\end{array}$ \\
\hline Escola pública & $\begin{array}{l}0,518^{* * *} \\
(0,154)\end{array}$ & $\begin{array}{c}0,607^{*} \\
(0,370)\end{array}$ & $\begin{array}{c}0,020 \\
(0,064)\end{array}$ \\
\hline $\begin{array}{l}\text { Gênero } \\
\text { (mulher) }\end{array}$ & $\begin{array}{c}0,092 \\
(0,140)\end{array}$ & $\begin{array}{c}0,198 \\
(0,335)\end{array}$ & $\begin{array}{c}-0,153^{* * *} \\
(0,058)\end{array}$ \\
\hline $\begin{array}{l}\text { Preconceito } \\
\text { social }\end{array}$ & $\begin{array}{c}-0,401^{* * *} \\
(0,145)\end{array}$ & $\begin{array}{l}-0,618^{*} \\
(0,356)\end{array}$ & $\begin{array}{l}-0,124^{* * *} \\
(0,062)\end{array}$ \\
\hline Intercepto & $\begin{array}{l}1,372^{* * *} \\
(0,198)\end{array}$ & $\begin{array}{l}-0,143 \\
(0,481)\end{array}$ & $\begin{array}{c}-0,418^{* * *} \\
(0,083)\end{array}$ \\
\hline Observações & 1359 & \multicolumn{2}{|c|}{2636} \\
\hline
\end{tabular}

Fonte: Elaboração própria com base nos dados da pesquisa "Medindo atitudes sobre assuntos socialmente sensíveis: o caso das cotas nas universidades brasileiras" (Turgeon, 2013).

Nota: $* p<0,1 ; * * p<0,05 ; * * * p<0,01$. 
Tabela C4

Modelo multivariado para cota para escola pública

\begin{tabular}{|c|c|c|c|}
\hline \multirow{2}{*}{ Variáveis } & \multirow{2}{*}{$\begin{array}{l}\text { Pergunta direta } \\
\text { est.(e.p.) }\end{array}$} & \multicolumn{2}{|c|}{ Experimento de lista } \\
\hline & & $\begin{array}{c}\text { Item sensivel } \\
\text { est.(e.p.) }\end{array}$ & $\begin{array}{c}\text { Itens-controle } \\
\text { est.(e.p.) }\end{array}$ \\
\hline Cor/raça branca & $\begin{array}{l}-0,257^{*} \\
(0,137)\end{array}$ & $\begin{array}{l}-0,307 \\
(0,332)\end{array}$ & $\begin{array}{l}-0,099 \\
(0,062)\end{array}$ \\
\hline Renda baixa & $\begin{array}{l}0,541^{* * * *} \\
(0,162)\end{array}$ & $\begin{array}{l}-0,037 \\
(0,390)\end{array}$ & $\begin{array}{c}0,129^{*} \\
(0,074)\end{array}$ \\
\hline Renda alta & $\begin{array}{l}0,390^{* * *} \\
(0,181)\end{array}$ & $\begin{array}{l}-0,090 \\
(0,445)\end{array}$ & $\begin{array}{l}0,172^{* *} \\
(0,084)\end{array}$ \\
\hline Escola pública & $\begin{array}{c}0,454^{* * * *} \\
(0,143)\end{array}$ & $\begin{array}{l}0,660^{*} \\
(0,342)\end{array}$ & $\begin{array}{c}0,105 \\
(0,064)\end{array}$ \\
\hline Gênero (mulher) & $\begin{array}{l}0,301^{* *} \\
(0,132)\end{array}$ & $\begin{array}{l}-0,026 \\
(0,339)\end{array}$ & $\begin{array}{c}-0,201^{* * *} \\
(0,062)\end{array}$ \\
\hline $\begin{array}{l}\text { Preconceito } \\
\text { educacional }\end{array}$ & $\begin{array}{c}-0,869^{* * *} \\
(0.133)\end{array}$ & $\begin{array}{l}-0,331 \\
(0,353)\end{array}$ & $\begin{array}{l}-0,113^{*} \\
(0,064)\end{array}$ \\
\hline Intercepto & $\begin{array}{l}0,520^{* * *} \\
(0,192)\end{array}$ & $\begin{array}{c}0,415 \\
(0,415)\end{array}$ & $\begin{array}{c}-0,545^{* * *} \\
(0,084)\end{array}$ \\
\hline Observações & 1346 & & \\
\hline
\end{tabular}

Fonte: Elaboração própria com base nos dados da pesquisa "Medindo atitudes sobre assuntos socialmente sensíveis: o caso das cotas nas universidades brasileiras" (Turgeon, 2013).

Nota: $* p<0,1 ; * * p<0,05 ; * * * p<0,01$.

\begin{abstract}
Affirmative action and social desirability

Affirmative action policies implemented in public universities in Brazil cover three main groups: public school students, low-income students, and black and indigenous students. Attitudes about affirmative action policy, when measured conventionally in surveys, can be contaminated by the social desirability bias effect. This article seeks to evaluate if attitudes about the different types of affirmative action policies recently adopted in Brazil are subject to the social desirability bias effect, and, if so, what are the determinants of this effect. To measure the social desirability bias effect and its determinants, we conducted a list experiment among 12.490 university students in 2013. The results reveal that attitudes about the three types of affirmative action policies are prone to a social desirability bias effect. We also find evidence that two individual-level determinants (self-interest and prejudice against the target group) and one contextual-level determinant (students' field of study) explain the social desirability bias effect.
\end{abstract}

Keywords: public opinion; affirmative action; social desirability bias; political attitude 


\section{Resumen}

Acción afirmativa y deseabilidad social

Las políticas de acción afirmativa implementadas en las universidades públicas de Brasil cubren tres grupos principales: estudiantes de escuelas públicas, estudiantes de bajo ingreso y estudiantes negros e indígenas. Las actitudes acerca de la política de acción afirmativa, cuando se miden de manera convencional en encuestas, pueden estar contaminadas por el efecto de sesgo de deseabilidad social. Este artículo busca evaluar si las actitudes sobre los diferentes tipos de políticas de acción afirmativa recientemente adoptadas en Brasil están sujetas al efecto de sesgo de deseabilidad social y, de ser así, cuáles son los determinantes de este efecto. Para medir el efecto del sesgo de la deseabilidad social y sus determinantes, llevamos a cabo un experimento de lista entre 12.490 estudiantes universitarios en 2013. Los resultados revelan que las actitudes sobre los tres tipos de políticas de acción afirmativa son propensas a un efecto de sesgo de la deseabilidad social. También encontramos evidencia de que dos determinantes a nivel individual (interés propio y prejuicio contra el grupo objetivo) y un determinante a nivel contextual (campo de estudio de los estudiantes) explican el efecto del sesgo de la deseabilidad social.

Palabras clave: opinión pública; acción afirmativa; sesgo de deseabilidad social; actitudes políticas

\section{Résumé}

\section{Action positive et désirabilité sociale}

Les politiques d'action positive mises en œuvre dans les universités publiques du Brésil couvrent trois groupes principaux: les étudiants des écoles publiques, les étudiants à faible revenu et les étudiants noirs et autochtones. Les attitudes à l'égard de la politique d'action positive, lorsqu'elles sont mesurées de manière conventionnelle dans les enquêtes, peuvent être contaminées par l'effet de biais de désirabilité sociale. Cet article cherche à évaluer si les attitudes à l'égard des différents types de politiques d'action positive récemment adoptées au Brésil sont sujettes à l'effet de biais de désirabilité sociale et, dans l'affirmative, quels sont les déterminants de cet effet. Pour mesurer l'effet de biais de désirabilité sociale et ses déterminants, nous avons mené une expérience de liste (list experiment) auprès de 12490 étudiants universitaires en 2013. Les résultats révèlent que les attitudes à l'égard des trois types de politiques d'action positive sont sujettes à un effet de biais de désirabilité sociale. Nous trouvons également que deux déterminants au niveau individuel (intérêt personnel et préjugés contre le groupe cible) et un déterminant au niveau contextuel (domaine d'études des étudiants) expliquent l'effet du biais de désirabilité sociale.

Mots-clés: opinion publique, action positive, biais de désirabilité sociale, attitudes politiques.

Artigo submetido à publicação em 10 de abril de 2019 . Versão final aprovada em 24 de junho de 2020.

Opinião Pública adota a licença Creative Commons CC-BY. 